\title{
PRENATAL IMMUNE CHALLENGE INDUCES DEVELOPMENTAL CHANGES IN THE MORPHOLOGY OF PYRAMIDAL NEURONS OF THE PREFRONTAL CORTEX AND HIPPOCAMPUS IN RATS
}

\author{
Moogeh Baharnoori ${ }^{1}$, Wayne Brake ${ }^{2}$ and Lalit K. Srivastava ${ }^{1}$ * \\ ${ }^{1}$ Douglas Mental Health University Institute \\ Department of Psychiatry, \\ McGill University, \\ 6875 LaSalle Blvd, \\ Verdun H4H 1R3 (QC) \\ Phone: (514)-761-6131 ext 2936 \\ Fax: (514)-762-3034 \\ ${ }^{2}$ Centre for Studies in Behavioral Neuroscience \\ Concordia University \\ * To whom all correspondence should be addressed \\ Phone: (514) 761-6131 ext 2936 \\ Fax: (514) 762-3034 \\ Email: lalit.srivastava@mcgill.ca
}




\section{Baharnoori $\mathrm{M}$ et al}

\section{ABSTRACT: \\ Background:}

The neural mechanisms by which maternal infections increase the risk for schizophrenia are poorly understood; however, animal models using maternal administration of immune activators suggest a role for cytokine imbalance in maternal/fetal compartments. As cytokines can potentially affect multiple aspects of neuronal development and the neuropathology of schizophrenia is believed to involve subtle temporo-limbic neurodevelopmental alterations, we investigated morphological development of the pyramidal neurons of the medial prefrontal cortex (mPFC) and hippocampus in rats that were prenatally challenged with the immune activator lipopolysaccharide (LPS).

Methods:

Pregnant Sprague-Dawley rat dams were administered with LPS $(100 \mu \mathrm{g} / \mathrm{kg}$, at E15 and E16) or saline. The brains of offspring were processed for Golgi-Cox staining at postnatal days (PD) 10, 35 and 56. Dendritic length, branching, spine density and structure were quantified using Neurolucida software.

Results:

At all ages, dendritic arbor was significantly reduced in mPFC and CA1 neurons of LPStreated animals. Dendritic length was significantly reduced in the mPFC neurons of LPS group at PD10 and 35 but returned to control values at PD60. Opposite pattern was observed in CA1 region of LPS animals (normal values at PD10 and 35, but a reduction at PD60). LPS treatment significantly altered the structure of CA1 dendritic spines at PD10. Spine density was found to be significantly lower only in layer V mPFC of PD60 LPS rats.

Conclusion: 
Baharnoori $\mathrm{M}$ et al

The study provides the first evidence that prenatal exposure to an immunogen dynamically affects spatio-temporal development of mPFC and hippocampal neurons that can potentially lead to aberrant neuronal connectivity and functions of these structures.

Key Words: Schizophrenia, Neurodevelopment, prenatal infection, dendrite arbor and Spine plasticity 


\section{Baharnoori $\mathrm{M}$ et al}

\section{INTRODUCTION:}

Evidence from epidemiology, imaging and neuropathological studies have led to the notion that early developmental aberrations within the central nervous system may form the starting point for later development of schizophrenia (Heinz et al., 2003;Marenco and Weinberger, 2000;McDonald and Murray, 2000;Brown et al., 2000). The complex mode of transmission of schizophrenia suggests important roles of both genetic and environmental factors in disease causation (Cannon and Clarke, 2005). Indeed, genetic approaches have recently identified a cluster of candidate genes associated with schizophrenia that may have potential roles in synapse development and function (Harrison and Weinberger, 2005). Possible contribution of early environmental factor to the origins of schizophrenia was recognized as early as by Kraepelin who proposed childhood inflammation of the brain and head injury as potential environmental risk factors (as cited by (Dean and Murray, 2005). Over the years, a number of early life environmental risk factors for schizophrenia, e.g., obstetric complications (Boksa and ElKhodor, 2003;Clarke et al., 2006) and maternal stress, infection and malnutrition (Brown and Susser, 2002; Khashan et al., 2008;McClellan et al., 2006;Penner and Brown, 2007) have been identified and investigated. Substantial evidence has accumulated in recent year suggesting that pre- or perinatal microbial infections may be one of the most important environmental risk factor for schizophrenia because of their potential to interfere with early brain developmental processes (Yolken and Torrey, 2008;Patterson, 2002). 


\section{Baharnoori $\mathrm{M}$ et al}

Animal studies support this hypothesis as rodent offspring prenatally exposed to influenza virus, a viral mimic, synthetic cytokine releaser polyriboinosinicpolyribocytidilic acid, (PolyI:C), or bacterial endotoxin lipopolysaccharide (LPS) displayed behavioral alterations that parallel to those observed in schizophrenia.

For example, Shi et al found that pregnant mice infected with influenza (at early pregnancy, E9.5) gave birth to offspring with deficits in prepulse inhibition (PPI) of the acoustic startle response and deficits in exploratory behavior, novel-object recognition and social interaction (Shi et al., 2003). Administration (poly I:C) at (E15) in rat leads to disruption in latent inhibition response in post-pubertal animals (Zuckerman and Weiner, 2005). Exposure to Poly (I:C) for 6 consecutive days (E12 to E17) in mice leads to greater response in methamphetamine -induced hyperlocomotion, deficits in PPI, and cognitive impairment in NORT compared with the PBS-treated controls(Ozawa et al., 2006) Single dose of PolyI:C in early/mid gestation (E9) in mice enhanced the sensitivity to the locomotor-stimulating effects of systemic amphetamine (AMPH) and MK-801 treatment in adulthood (Meyer et al., 2007a) Latent inhibition defects was observed in animals born to dams treated with Poly(I:C) on gestational age(GD) 6, 9 or 13, but not in those on GD17. In contrast, impairment in unconditional stimulus pre-exposure effect was seen in all Poly (I:C) treatment groups, regardless of age of treatment (Meyer et al., 2006b). Administration of a bacterial endotoxin, lipopolysaccaride, LPS, at GD17 and 18 induces significant increase in amphetamine-induced locomotion and facilitated acoustic startle responses in adult rats (Fortier et al., 2004). Furthermore, PPI was significantly 


\section{Baharnoori $\mathrm{M}$ et al}

decreased in adult rat offspring following prenatal LPS treatment at E15-16 and E18-19 (Fortier et al., 2007).

The mechanisms by which maternal immune activation leads to alterations in adult offspring behavior are not fully understood; however, effects on aspects of brain developmental processes are indicated by a number of evidence. After maternal immune activation by influenza infection, LPS, or poly(I:C), cytokine levels are altered in the maternal serum as well as the amniotic fluid, placenta, and fetal brain (Ashdown et al., 2006;Beloosesky et al., 2006;Cai et al., 2000;Gayle et al., 2004;Gilmore et al., 2005; Meyer et al., 2006a;Paintlia et al., 2004;Urakubo et al., 2001). In maternal Poly IC model, blocking pro-inflammatory interleukin (IL)-6 or increase in the concentration of anti-inflammatory IL-10 strongly attenuates the effects of maternal immune activation on fetal brain development (Meyer et al., 2006a;Smith et al., 2007). Further, IL-10, shows the similar neuro protective effect in presence of prenatal insult with LPS (Agnello et al., 2000;Kremlev and Palmer, 2005;Lynch et al., 2004;Rivera et al., 1998).

There is evidence from in vitro and in vivo studies that cytokines regulate neuronal development (Kessler et al., 1998;MalekAhmadi, 1996;Marx et al., 2001;Merrill, 1992;Patterson and Nawa, 1993;Rothwell and Hopkins, 1995;Urakubo et al., 2001). Particularly relevant in the present context are the findings that cytokines detrimentally affect the developing hippocampal and cortical neurons. In vitro study shows that the inflammatory cytokines TNF-a, IL-1b, and IL-6 can inhibit the development of dendrites in embryonic cortical neurons, consistent with the neuropathology of schizophrenia 


\section{Baharnoori $\mathrm{M}$ et al}

(Gilmore J.H. et al., 2004;Marx et al., 2001). In rats, neonatal administration of proinflammatory cytokines (Tohmi et al., 2004) or leukemia inhibitory factors (Watanabe et al., 2004) induce future psychobehavioral and/or cognitive impairments. With regard to brain anatomical changes reported in schizophrenia, it is notable that alterations in pyramidal neuron morphology in prefrontal cortical and limbic structures is a widely replicated finding in post-mortem studies (Glantz and Lewis, 2000;Kolluri et al., 2005;Casanova and Rothberg, 2002a) as well as in putative neurodevelopmental models of schizophrenia (Flores et al., 2005;Juarez et al., 2008; Wedzony et al., 2005).

Therefore, the aim of the present study was to make a quantitative assessment of pyramidal neuronal morphology at defined neonatal and pre- and post-pubertal developmental periods in mPFC (layer III, as main recipient of excitatory projections, layer $\mathrm{V}$ that receives large dopamine input) and $\mathrm{CA} 1$ region (for its key role in glutaminergic transmission), following LPS $(100 \mu \mathrm{g} / \mathrm{kg})$ challenge at embryonic days 15 and 16, a period which approximates mid to late pregnancy in human.

Our data showed that prenatal LPS exposure is able to induce significant age-dependent cytoarchitectural changes in pyramidal neurons of mPFC and hippocampus that may affect the proper connectivity and neuronal transmission in these regions leading to cognitive and behavioral impairments reported in prenatally infected offspring. 


\section{METHODS:}

Animals. Timed Pregnant Sprague-Dawley rats (Charles River Laboratory, Quebec) were individually housed in temperature and humidity-controlled Plexiglass cages on a $12 \mathrm{~h}$ light/dark cycle with ad libitum access to food and water. All procedures were performed in strict accordance with the guidelines established by the Canadian Council on Animal Care and were approved by the McGill University Animal Care Committee. The animals were injected intraperitoneally (ip) with $100 \mu \mathrm{g} / \mathrm{kg}$ of LPS (from E. coli serotype 0111:B4, L-2630, Sigma, Canada) once daily, for two consecutive days at E15-16. Another set of dams with injection of a corresponding amount of sterile saline (ip) were used as controls ( $n=5$ per group).

Measurement of body temperature. The animals were handled for 4 days before injections and for habituation with the temperature measurement procedure basal body temperature has been measured for 4 consecutive days in the morning with rat rectal probe (BAT-10 Thermometer, Physitemp instruments INC, USA). In the day of injection (E15 and E16) changes in core body temperature were monitored in both LPS and saline treated animals every 2 hour, for 8 hours after injection. The maximum rise of $1{ }^{\circ} \mathrm{C}$ above basal temperature assumed as proper response to LPS. The hyperthermic and hypothermis animals excluded from study (Fig 1.)

On the day of birth, a small quantity of unwashable ink was injected into one of the paws of the pups to mark the treatment and then they were cross-fostered with surrogate dams in mixed litters. Only male pups were retained for the study. At Postnatal 10 (P10) 5 pups 
per treatment (one from each dam) were anesthetized with Ketamine-Xylazine mixture $(100 \mathrm{mg} / \mathrm{kg}$ Ketamine, $0.8 \mathrm{mg} / \mathrm{kg}$ xylazine) and transcardially perfused with $0.9 \%$ saline and their brain processed for Golgi staining.

The rest of the pups were weaned at PD21 and housed as two animals/same treatment per cage. At PD35 and PD60, 7 animals per treatment (1-2 pups per dam) were anesthetized and their brains perfused as above for Golgi staining.

Modified Golgi-Cox staining. The brains were processed for Golgi-Cox staining as described by (Gibb and Kolb, 1998). The brains were immersed in $20 \mathrm{ml}$ of Golgi-Cox solution and stored for 21 days in the dark. Then the solution was replaced with $30 \%$ sucrose and kept for 5 more days. Brain sections of $200 \mu \mathrm{m}$ thickness at coronal plane at the level of medial prefrontal cortex (mPFC) and hippocampus were cut using a Vibrotome (VT1000S, Leica). The sections were placed on microslides (Snow-coat extra, Surgipath) and the blotted slides kept in a humid chamber overnight. The next day, the sections were developed in ammonium hydroxide for 30 minutes and then placed in Kodak film fixer for another 30 minutes. Sections were washed in water and dehydrated in graded concentration of ethanol $(70 \%, 95 \%, 100 \%$, and 100\%) and finally mounted using Permount (Fisher, SP15-100).

Morphological analysis. Basilar dendrites of pyramidal neurons in layer III and V of mPFC (Cg1 and Cg3, plate 7-9 of (Paxinos G and Watson C, 1986), or Cg1 and Prelimbic cortex, plate 8-10 of (Paxinos G and Watson C, 2007) and pyramidal neurons 


\section{Baharnoori $\mathrm{M}$ et al}

in the CA1 region of the hippocampus (CA1, plate 58-63 of (Paxinos G and Watson C, 2007) were selected for analysis. A person blind to the conditions of the study performed neuron selection and tracing. Pyramidal neurons were identified by their specific triangular shape of the soma and their apical extensions toward pial surface. From each animal, 5 sections were selected per region and in each section, one neuron per hemisphere was reconstructed three-dimensionally using computer based neuron tracing system (NEUROLUCIDA, MicroBrightField, Williston, VT).

A Leica microscope (Leica DM 5000B) together with a motor stage equipped with position sensing transducers on the XYZ-axes was used to trace each neuron at low magnification (250X). Specific criteria were set for the Golgi-impreganted neurons to be included in our study. First, they should be located in proper area, either mPFC (Layer III or layer V) or CA1 region of hippocampus. Second, each neuron should be completely impregnated with Golgi material and the typical dark staining should be visible in all dendritic branches as well as spine structure. Third, the selected isolated neurons' process sould not be covered by the branches of neighboring neurons.

A Sholl analysis was performed on each of the three-dimensionally reconstructed neurons to calculate the number of intersections and dendritic length per concentric Sholl ring $(10 \mu \mathrm{m}$ interval $)$ in order to gather information on the changes in dendritic tree complexity. Total length of basilar dendrites was measured for each treatment and in all the three regions. All the dendritic segments has been reconstructed and based on the data 


\section{Baharnoori $\mathrm{M}$ et al}

Total length of basilar dendrites was measured for each treatment and in all the three regions.

For spine density measurement, one terminal dendrite from the third order tip (minimum length $20 \mu \mathrm{m}$ ) of each selected neuron was used to count spines at a magnification of 5000X. The results are expressed as number of spines/10 $\mu \mathrm{m}$. We only traced the spines that were fully attached to dendritic segments and avoided the spines whose structure was not completely visible in the microscope. For each selected dendrite, spine density and spine structure was evaluated as spine length $(\mu \mathrm{m})$ surface area $\left(\mu \mathrm{m}^{2}\right)$ and volume $\left(\mu \mathrm{m}^{3}\right)$ according to Neurolucida software.

The length of a spine is computed by summing up the length of the spine from the point it is connected to the branch to the end of spine. The volume and surface are computed by modeling the spine as frusta (3D reconstruction; like a shape of right circular cone that has been truncated).

Statistical analysis. Data on mean group differences in total dendritic length, spine density and individual structural data of each spine (volume, length and surface area) were analyzed by student's $t$ test. In addition, for dendrite arborization pattern, Sholl ring analysis data (number of intersections and dendrite length per each radius) was analyzed by two-way ANOVA with treatment and radius as factors followed by post-hoc test (Prism software). The level of significance was set at $P<0.05$ for all analyses. 
Baharnoori $\mathrm{M}$ et al

\section{RESULTS:}

Prefrontal cortex. At postnatal day 10, 2-way ANOVA of number of intersections displayed significant main effect of treatment in dendrite arborization pattern $\left(F_{(1,192)}\right.$ $=64.36 ; P<0.0001)$, significant main effect of radius and a significant interaction between treatment $\mathrm{x}$ radius ( $\mathrm{F}$ and $\mathrm{p}$ values). Bonferroni Post hoc test revealed significant decrease in number of intersections on proximal dendrites of LPS-treated animals compared to saline controls at radius 20,30 and $40 \mu \mathrm{m}, P<0.0001)$ (Fig. 2A). As expected, main effect of radius was always significant, so for the sake of brevity, it will not be mentioned for each region and age-point.

The effect of LPS treatment on layer III PFC neurons remained significant through development at $\mathrm{P} 35\left(F_{(1,360)}=23.16 ; P<0.0001\right.$, Fig.3A $)$ and $\mathrm{P} 60\left(F_{(1,492)}=19.23\right.$; $P<0.0001$, Fig. 4A). Dendrite branching pattern was also significantly lower in layer V of LPS group comparing with Saline controls $\left(F_{(1,396)}=22.11 ; P<0.0001\right)$

(Fig. 5A) In response to LPS exposure, total dendritic length was significantly reduced in an age-dependent manner in neonatal $(\mathrm{P}=0.0172)$ (Fig. $2 \mathrm{~B})$ and pre pubertal age in layer III of PFC ( $\mathrm{P}=0.008)$ ( Fig.3B) In post pubertal animals, total dendritic length in LPS treated animals showed trend of decrease in layer III and V however it did not reach to significant point (Fig. 4B, 5B) Dendritic spine density in LPS group was comparable with saline controls in neonatal and pre pubertal offspring but it came out significantly lower in adult animals in layer $\mathrm{V}$ of $\mathrm{PFC}(P=0.00287)($ Fig.5C, Fig.9) 


\section{Baharnoori $\mathrm{M}$ et al}

There was no significant effect of LPS in spine structure (Spine length, spine surface area or spine volume in PFC during development.

Hippocampus, CA1. Two way analysis of variance on number of dendrite intersections showed an overall significant decrease (ANOVA doesn't show significant decrease, it shows siginificant effect of a factor in analysis, e.g., treatment or radius; Post-hoc test reveals significant difference - increase or decrease!!!) in dendrite complexity in LPS treated animals with no significant interaction between LPS and radius in neonatal $(F$ $(1,192)=9.60 ; P=0.002)($ Fig. $6 \mathrm{~A})$, pre pubertal rats $\left(F_{(1,300)}=13.02 ; P=0.0004\right)($ Fig. $7 \mathrm{~A})$ Pyramidal neurons in CA1 region showed significant reduction in the complexity of dendritic tree in response to prenatal LPS treatment (number of intersections, $F_{(1,336)}$ $=56.13 ; P<0.0001)$. In addition, post hoc analysis revealed a significant interaction between LPS and radius $(P=0.0002$, radius $80 ; P<0.01$, radius $90 ; P<0.01$, radius 100 ; $P<0.01$, radius 110; $P<0.001$, radius120; $P<0.05$, radius130; $P<0.05$ ) (Fig. $1 \mathrm{C}, \mathrm{C}^{\prime}$ and Fig.8A). Student's $t$ test also showed prenatal LPS induces significant decrease in total dendrite length at post-pubertal ages $(P=0.0164)$ (Fig.8B).

There was no statistical difference in spine density between two groups at any age points. but interestingly at neonatal period prenatal treatment with LPS significantly reduced different parameters of spine structure such as spine length (Saline; $1.850 \mu \mathrm{m} \pm 0.041$ versus LPS; $1.592 \mu \mathrm{m} \pm 0.053, P=0.005$ ), spine surface area (Saline; $0.374 \mu \mathrm{m}^{2} \pm 0.008$ versus LPS; $0.323 \mu \mathrm{m}^{2} \pm 0.011, P=0.006$ ) and spine volume (Saline; $0.0059 \mu \mathrm{m}^{3} \pm 0.0001$ versus LPS; $\left.0.0051 \mu \mathrm{m}^{3} \pm 0.001, P=0.0001\right)$ (Fig.6D, E and F). 


\section{Baharnoori $\mathrm{M}$ et al}

The results need to be streamlined as I have done in the first para of the result. It should start with the values of ANOVA - significant main effect of this or that (provide F and $\mathrm{p}$ values). Then you say post-hoc analysis revealed that LPS-treated groups showed significant decrease. In some cases, you only have a main effect of treatment and/or radius but no post-hoc significance. So you should write that the 2-way ANOVA showed significant main effect of treatment and radius. However pos-hoc analysis did not reveal significant effect at any particular radius suggesting that LPS treatment had a general effect on the reduction of dendritic spine branching.

\section{DISCUSSION:}

The present study demonstrates significant changes in the cytoarchitecture of pyramidal neurons of the mPFC and hippocampus in neonatal and pre and post-pubertal rats in a maternal infection model of schizophrenia. Our results showed an across the board decrease in dendritic arborization at all ages. It seems that prenatal LPS challenge permanently alter neuronal outgrowth in developing animals at least in the two brain regions studied. Interestingly, other morphological alterations in LPS treated offspring displayed dynamic rather than permanent pattern during development. For example, basilar total dendritic length was significantly decreased in the layer $3 \mathrm{mPFC}$ of P10 and P35 LPS offspring, while no significant changes were observed in P60 animals. This pattern is opposite to what was seen in the hippocampal CA1 neurons where total dendritic length was significantly reduced only at post-pubertal age. Prenatal LPS treatment also changed spine density and structure in an age and region specific manner. 


\section{Baharnoori $\mathrm{M}$ et al}

Our observations indicate that the mechanisms that promote dendritic branching may be more particularly affected by prenatal LPS, whereas mechanisms that regulate dendrite elongation and spine formation may be altered in a complex manner interacting with development and experience. Interestingly, in several putative animal models of schizophrenia where developmental changes in brain morphology has been studied, a common finding is that there is development and age specific changes in brain morphology and molecules involved in neurodevelopment. For example, in DISC-1 dominant negative mutant mice, lateral ventricular volume reduction was observed at 6 weeks and not at 3 months (Hikida et al., 2007) and Fatemi et al reported reductions in brain volume and white matter atrophy only at PD35 following prenatal infection of mice with influenza virus (Fatemi et al., 2008)

It is known that intrauterine exposure to immune activators such as LPS, influenza virus, and polyI:C results in brain injuries and adversely affects different population of neurons in developing brain (Carvey et al., 2003;Elovitz et al., 2006; Ling et al., 2002;Rousset et al., 2006;Sharangpani et al., 2008;Wang et al., 2006;Wang et al., 2007). While cytoarchitectural changes in the brains of prenatal LPS treated animals has not been reported, mice with prenatal influenza virus have been reported to show abnormal corticogenesis and neuronal migration (Fatemi et al., 1999). Prenatal influenza also leads to pyramidal cell atrophy and gliosis in the hippocampus and cortex which persists through development (Fatemi et al., 2002b;Fatemi et al., 2002a). Similarly, after prenatal administration of a viral mimic, polyI:C, severe cell loss and pyknotic pattern in was observed in CA1 region of mice offsping (Zuckerman et al., 2003). That some of the 


\section{Baharnoori $\mathrm{M}$ et al}

brain changes in prenatally immune challenged animals may be due to pro inflammatory cytokines is suggested by experiments on prenatal IL-6 showing significant astrogliosis and neuronal loss in the hippocampus of offspring (Samuelsson et al., 2006).

The mechanisms mediating neuronal changes in the offspring are not directly addressed in our study, however, LPS-induced production of pro inflammatory cytokines, viz, IL-6, IL1 $\beta$ and TNF $\alpha$ that have been documented to have effects on various aspects of neuronal development and injury may be likely mediators (Jeohn et al., 1998;Marx et al., 2001). For example In vitro experiments on cortical neurons culture showed that TNF $\alpha$ inhibits cortical dendrite development by reducing total dendritic length and number of branching points, and at higher doses IL- 6 and IL-1 $\beta$ also have the same effects (Gilmore J.H. et al., 2004). TNF- $\alpha$ also inhibits outgrowth and branching of hippocampal neurons through a mechanism modulated by small GTPase Rho (Neumann et al., 2002). In vivo administration of IL1 $\beta$ in rats decreases mRNA and protein expression of insulin-like growth factor, IGF-1 which plays role in neuronal outgrowth during brain development (Fan et al., 1996). It should be noted, however, that literature on changes in pro inflammatory cytokines in fetal brain after systemic maternal administration of LPS is still inconclusive, in contrast to intrauterine administration of LPS where up regulation of pro inflammatory cytokine, TNF- $\alpha$ was observed in fetal compartments (Ning et al., 2008). For example, Cai et al showed increased TNF- $\alpha$ and IL1 $\beta$ mRNA and protein in fetal brain after relatively high doses of systemic maternal LPS at gestational day 18 (Cai et al., 2000) while Ashdown et al noted no significant differences in TNF- $\alpha$, IL-6 or IL$1 \beta$ in fetal rat brain after $50 \mu \mathrm{g} / \mathrm{kg}$ at same gestational age. However, Ashdown et al 


\section{Baharnoori $\mathrm{M}$ et al}

showed significant up regulation of IL- $1 \beta$ in fetal plasma and up regulation of TNF- $\alpha$, IL6 and IL-1 $\beta$ in placenta (Ashdown et al., 2006). Similar finding was reported in the level of TNF- $\alpha$ and IL- 6 following administration of the same dose of LPS at E16 (Urakubo et al., 2001). Therefore, it seems that cytokine responses in fetal brain to immune challenge are dependent on doses and timing of maternal LPS injection. While TNF- $\alpha$ and other pro inflammatory cytokines can potentially be involved in the morphological changes we observe in our model, we need to measure cytokine levels before we can discuss their effects any further.

Maternal stress due to LPS treatment could also be a factor in brain abnormality in the offspring. Reduced neuronal proliferation, neurogenesis and increased cell loss have been reported in offspring that were exposed to physical stressors during gestational days (Coe et al., 2003;Kawamura et al., 2006;Lemaire et al., 2000;Mandyam et al., 2008). Further, cytoarchitectural changes in the form of reduced dendritic length, complexity of dendritic tree and spine density have been reported in offspring prenatally exposed to various stressors (Fujioka et al., 2006;Michelsen et al., 2007;Murmu et al., 2006).

Dendritic outgrowth, branching and spine morphology are under the influence of several intrinsic and extrinsic factors (Jan and Jan, 2003; Scott and Luo, 2001). For example, neurotrophins such as nerve growth factor (NGF) and brain-derived neurotrophic factor (BDNF) acting as extrinsic factors can effect neurite outgrowth and dendrite morphology of cortical and hippocampal neurons (Deumens et al., 2006; Labelle and Leclerc, 2000; Ring et al., 2006). Endotoxin immune challenge and pro inflammatory cytokines 


\section{Baharnoori $\mathrm{M}$ et al}

are known to alter the expression of BDNF and NGF in the hippocampus and different cortical regions including the PFC (Gilmore et al., 2003;Guan and Fang, 2006;Schnydrig et al., 2007). Thus, it is possible that changes in the level of neurotrophic factors in the cortex and hippocampus due to prenatal LPS may participate in the dendrtic changes observed in our studies. Among extrinsic factors, it is worth noting that reelin that regulates dendritic growth and neuronal lamination (MacLaurin et al., 2007;Olson et al., 2006) was reported to be reduced in the hippocampus CA1 and mPFC regions in prenatal PolyI:C or influenza virus treated mice as well as in schizophrenia brains (Fatemi et al., 1999; Meyer et al., 2006c;Meyer et al., 2007b;Fatemi et al., 2000).

Pyramidal neurons are the main source of excitatory glutamate neurotransmission. Impoverished pattern of dendrite growth and arborization will have consequences for the neurons' ability to build up enough and efficient connections through incoming afferents, which could include reception of fewer excitatory and inhibitory inputs from other parts of brain during critical stages of brain development. For example, in the PFC it may relate to cortico-cortical inputs and midline thalamus nuclei, which make synapses on dendrites of pyramidal neurons in layer III (Kuroda et al., 1998;Wang and Shyu, 2004). In CA1, decrease of dendritic arbor may affect its ability to receive afferents from CA3 region as well as glutamatergic and GABA afferents from the medial septal formation (Colom et al., 2005; Kajiwara et al., 2008). It is thus possible that these rearrangements in neuronal circuitry may explain some aberrant PFC and hippocampus related tasks such as object recognition, spatial learning and working memory deficits that have been 


\section{Baharnoori $\mathrm{M}$ et al}

reported in prenatally immune challenged animals (Lante et al., 2007; Meyer et al., 2007c;Ozawa et al., 2006;Samuelsson et al., 2006).

Interestingly, data from dendrite arbor in $\mathrm{mPFC}$ at PD 10 revealed a significant decrease in the number of perisomal and proximal dendritic branches compared with distal segments. In neonatal period, the somas and proximal dendritic segments of cortical pyramidal neurons specifically receive inhibitory inputs from fast-spiking, GABAergic interneurons (Chattopadhyaya et al., 2004). It is noteworthy that neurodevelopmental deficits of GABAergic interneurons along with gamma oscillation disruption have been reported in PFC of schizophrenia subjects and in a number of animals models (bdulMonim et al., 2007;Beasley and Reynolds, 1997;Reynolds et al., 2002;Spencer et al., 2003; Spencer et al., 2004). GABAergic changes such as increased postsynaptic GABAA receptor subunit $\alpha 2$ in ventral hippocampus and basolateral nucleus, have been reported in prenatal poly I:C treated mice (Nyffeler et al., 2006). Development of GABAergic neurons starts at midgestation age and is not complete till the end of adolescence (Di, 2007; Woo and Lu, 2006). One can speculate that disruptions in GABAergic neuron input around this age in prenatal LPS-treated rats may partly contribute to dendrtitic changes reported.

Prenatal LPS treatment also resulted in significant decrease in spine structure (e.g. spine volume, surface area and length) in hippocampus CA1 region at P10. This is an interesting observation since $\mathrm{P} 7-10$ is time of maximum spinogenesis in the hippocampal formation (Fiala et al., 1998;Harris, 1999). The fact that our LPS treated animals showed 


\section{Baharnoori $\mathrm{M}$ et al}

significant decrease in spine volume implies a very early aberration in spine formation and impairment in synaptogenesis in hippocampus. Decreased spine volume at P10 might mean that excitatory connections that are made at this time are probably immature and unable to drive future development of hippocampus connectivity which may explain the persistent decrease in dendrite arborization and branching during development in LPS exposed offspring.

In post-pubertal rats, analysis showed significant decrease in spine density of basilar dendrites in layer V PFC pyramidal neurons in prenatal LPS group. Alterations in layer V spines may likely affect interactions between glutamatergic and dopaminergic transmission in the PFC and output of pyramidal neurons to sub cortical targets such as mesolimbic dopamine areas (Ding et al., 2001). One of the roles of DA inputs in the PFC is to gate excitatory inputs coming from subcortical regions (Onn et al., 2006;Seamans and Yang, 2004). It has been reported that DA depletion of PFC following ventral tegmental area lesions causes decrease in spine density in neurons of layer V mPFC (Wang and Deutch, 2007). Consistent with mesolimbic DA system deregulation, several studies show dopamine related behavioral disturbances like deficits in psychostimulantinduced locomotion, prepulse inhibition of startle and latent inhibition in animals prenatally treated with LPS, poly I:C or IL-6 (Fortier et al., 2004;Fortier et al., 2007; Ozawa et al., 2006; Romero et al., 2008;Smith et al., 2008).

The cytoartitectural changes reported here are reminiscent of morphological changes reported in several putative animal models for schizophrenia as well as in the brain of 
schizophrenia patients. Post-mortem studies in schizophrenia have demonstrated altered number of dendritic branches in layer III and V of prefrontal cortex and decreased dendritic spine density in the dorsolateral prefrontal cortex (Black et al., 2004;Broadbelt et al., 2002;Casanova and Rothberg, 2002b;Garey et al., 1998;Glantz and Lewis, 2000; Kalus et al., 2000). Significant decrease in spine density and total dendritic length of PFC pyramidal neurons has also been reported following neonatal hippocampus lesion, a widely-used developmental animal model for schizophrenia (Flores et al., 2005). However, both reduction and increase in the number of prefrontal dendritic spines are reported in some pharmacological animal models of schizophrenia, e.g., sub chronic phencyclidine administration (Flores et al., 2007;Hajszan et al., 2006).

In conclusion, our results show that prenatal LPS challenge leads to morphological abnormality in pyramidal neurons that starts at very early postnatal days, with some abnormal features persisting through to postnatal days while others showing a more dynamic pattern. Taking into account that prenatal immune-challenged animals display significant deficits in schizophrenia-related behaviors, we suggest that alterations in pyramidal neuronal morphology may be an important mechanism underlying such behavioral changes. 
Fig. 1. Photomicrograph showing representative Golgi-Cox impregnated pyramidal neurons, upper panel layer III PFC at P10, Saline (A) versus LPS (A'), middle panel layer III PFC at P60 Saline (B) versus LPS(B') and lower panel hippocampus CA1 area at P60 Saline (C) versus LPS(C').

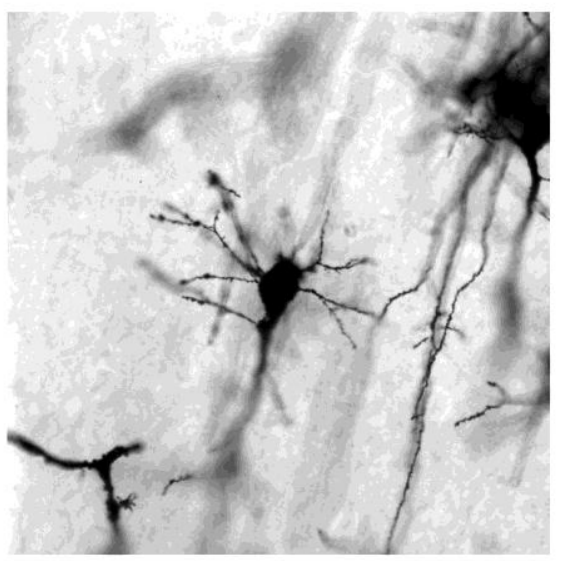

(A)

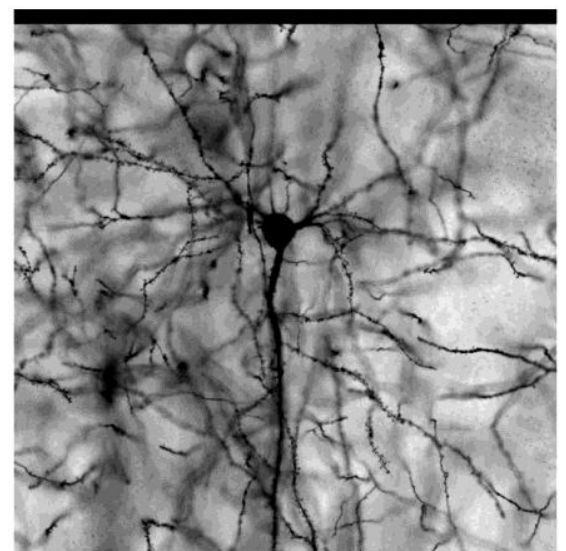

(B)

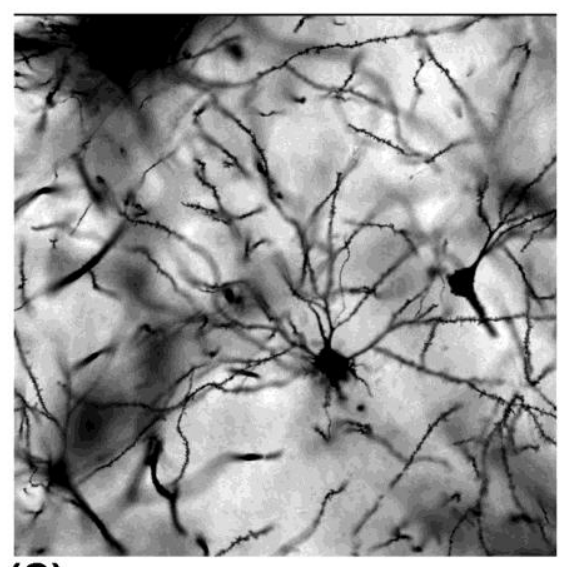

(C)

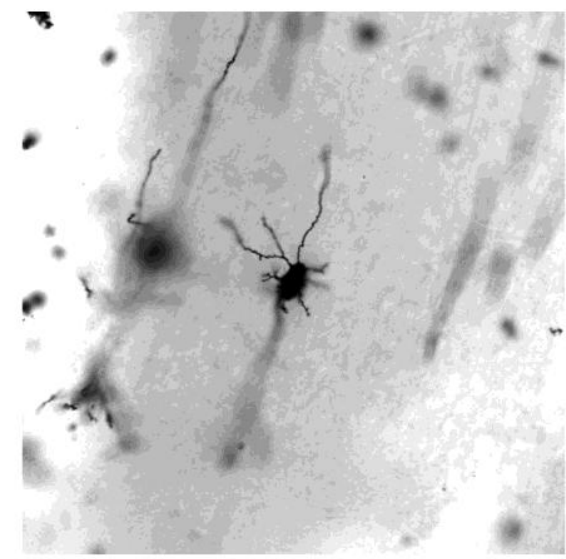

(A')

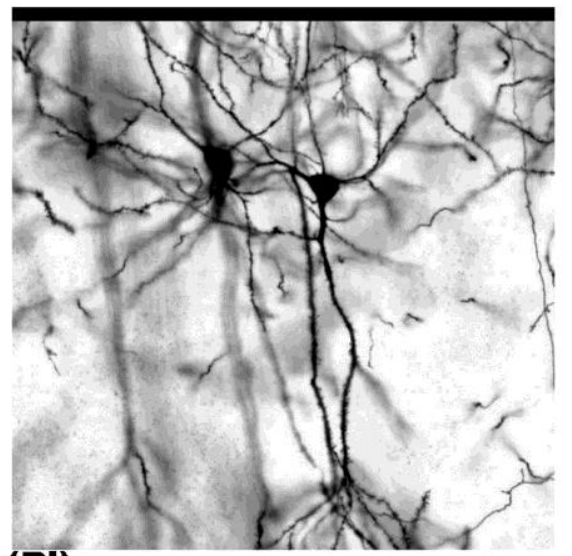

(B')

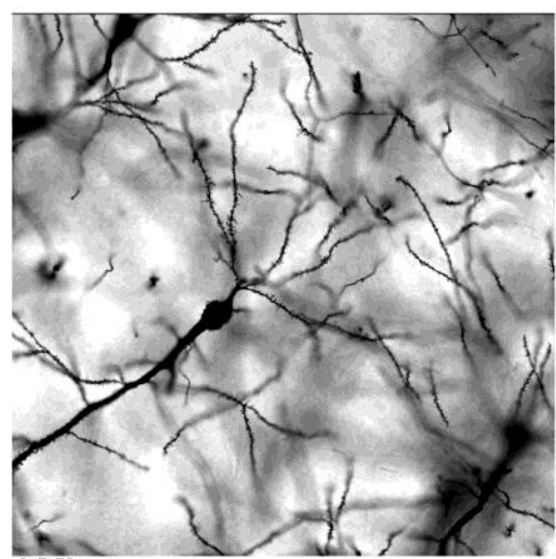

(C') 
Fig. 2. Pyramidal neuron morphology in layer III PFC at P10. (A) Number of dendritic intersections per each Sholl radius $(10 \mu \mathrm{m})(P<0.001)$ ( radius 20, 30 and 40*** $P<0.001$, radius 50, $* * P<0.01)$. (B) Total dendritic length $(\mu \mathrm{m})(* P<0.05)$ and $(\mathrm{C})$ Dendritic spine density (number of spines per $10 \mu \mathrm{m}$ ).

\section{PFC layer III, P10}

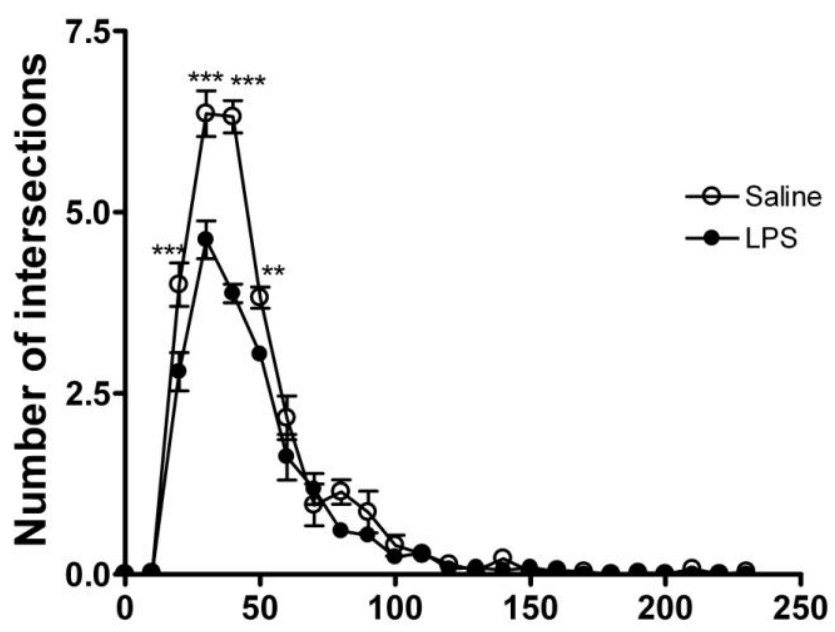

(A)

Radius

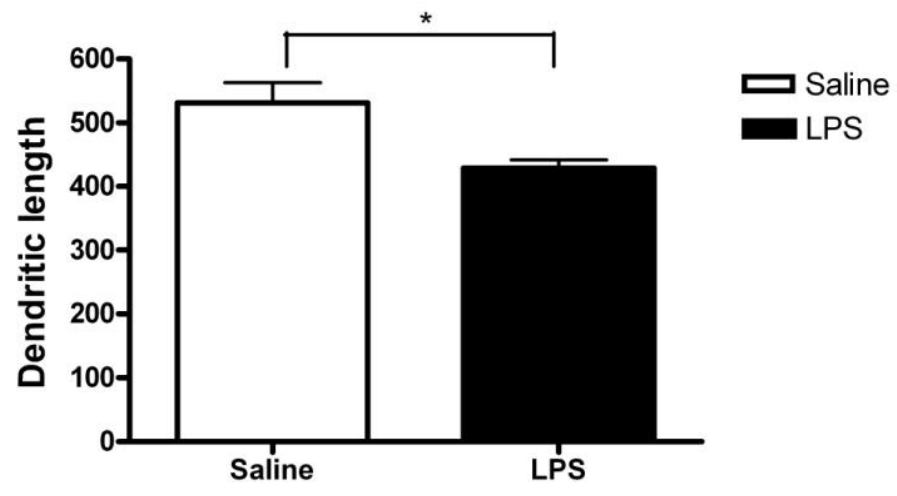

(B)

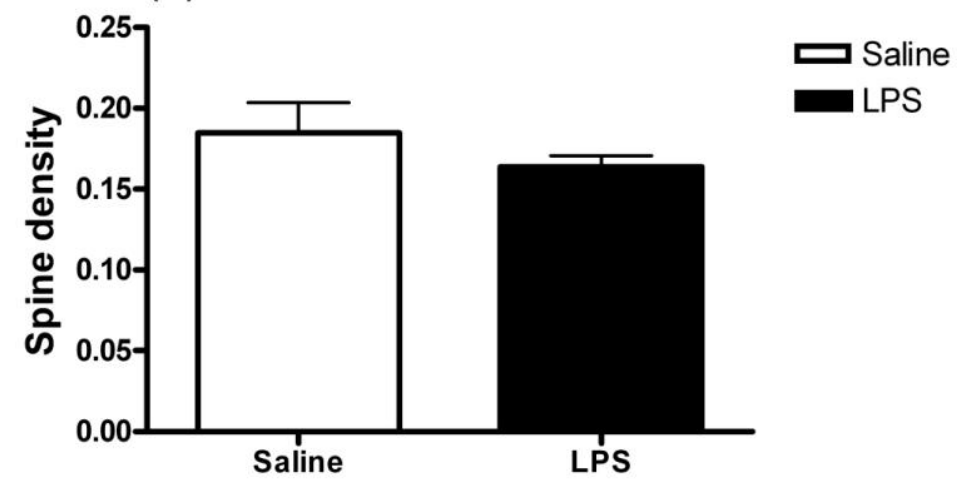

(C) 
Fig. 3. Pyramidal neuron morphology in layer III PFC at P35. (A) Number of dendritic intersections per each Sholl radius $(10 \mu \mathrm{m})(* * P<0.001)$. (B) Total dendritic length $(\mu \mathrm{m})$ and $(\mathrm{C})$ Dendritic spine density (number of spines per $10 \mu \mathrm{m}$ )
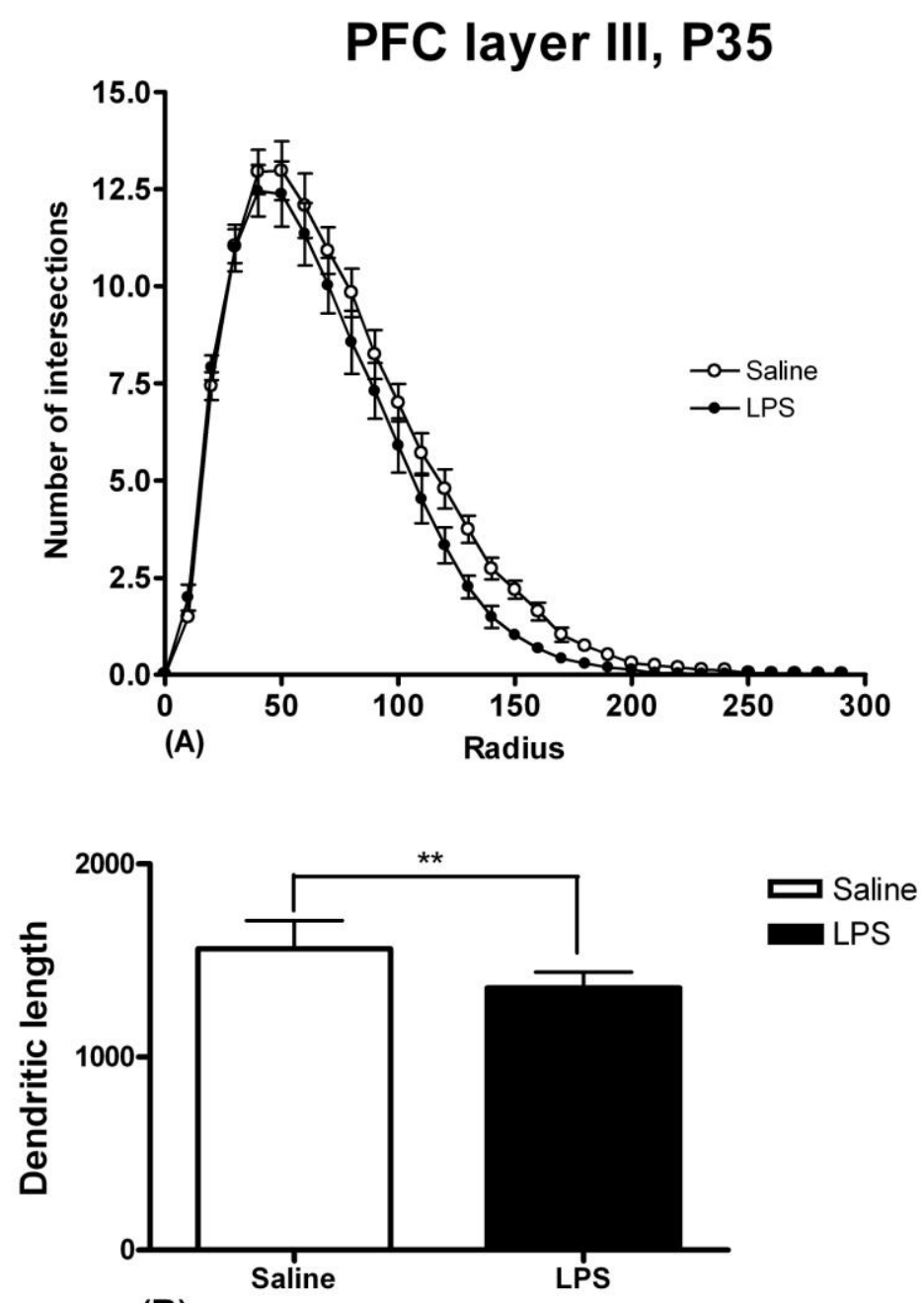

(B)

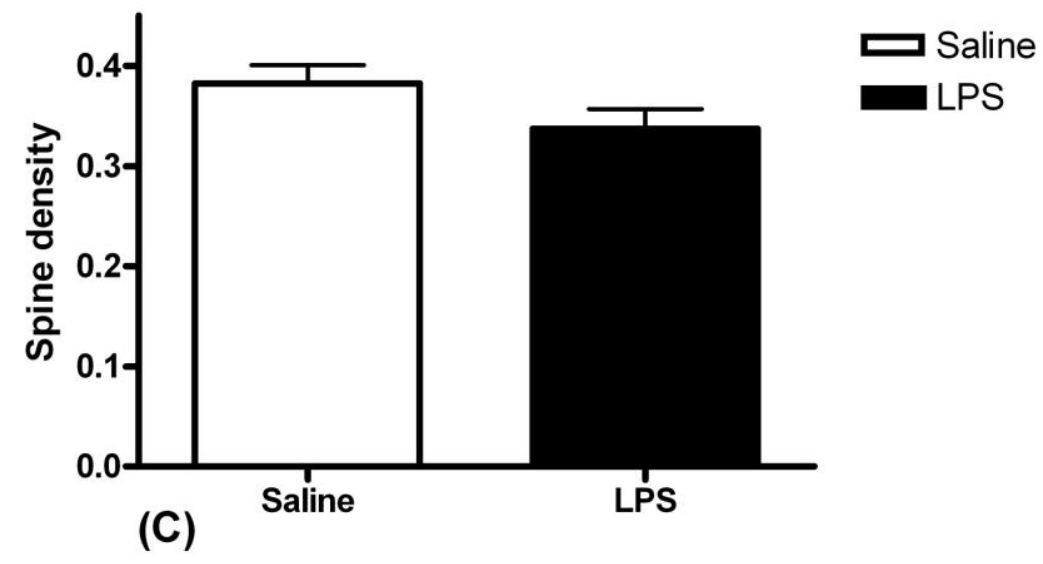


Fig. 4. Pyramidal neuron morphology in layer III PFC at P60. (A) Number of dendritic intersections per each Sholl radius $(10 \mu \mathrm{m})(P<0.001)$. (B) Total dendritic length $(\mu \mathrm{m})$ and $(\mathrm{C})$ Ddendritic spine density (number of spines per10 $\mu \mathrm{m}$ ).

\section{PFC layer III, P60}
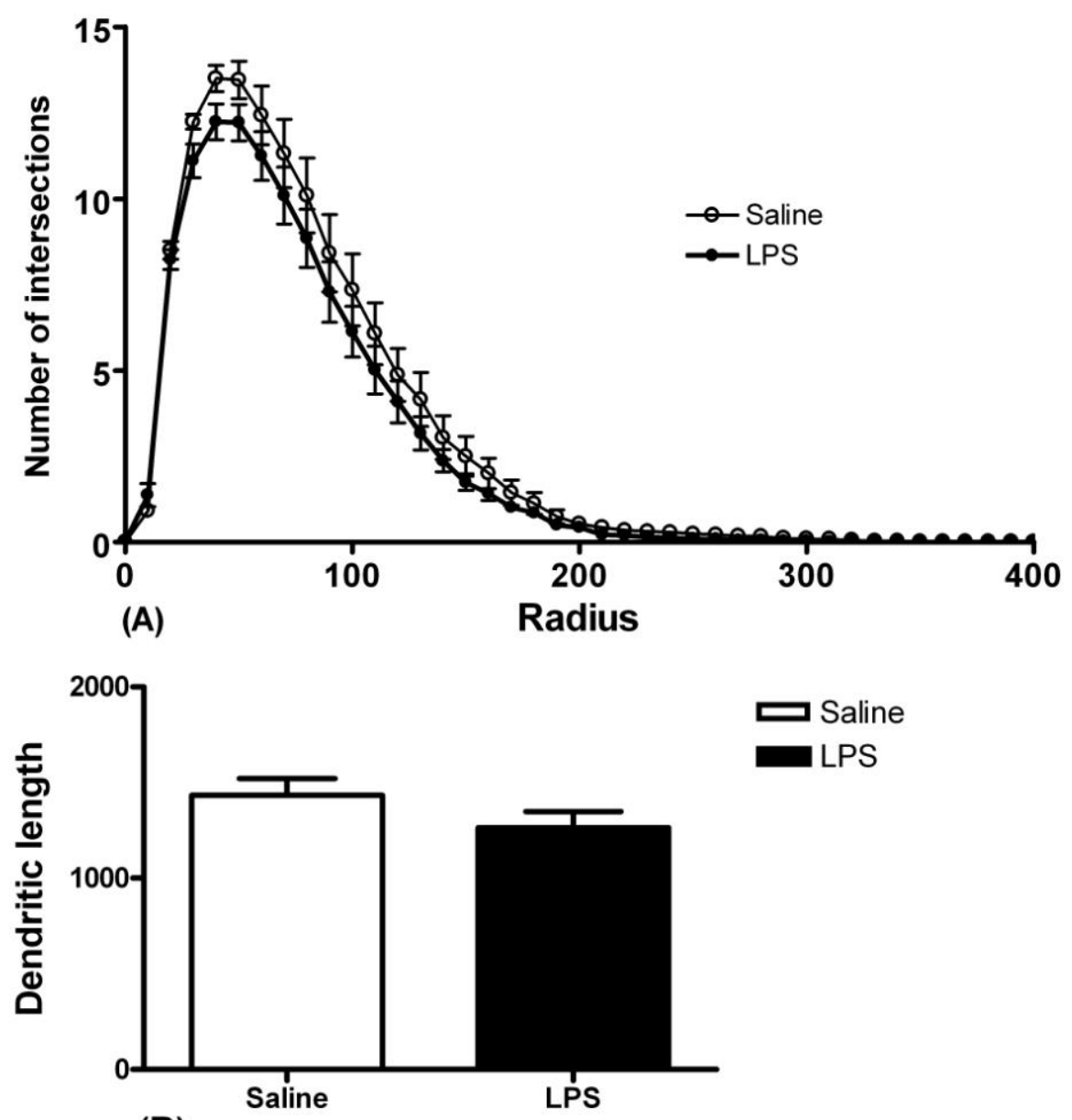

(B)

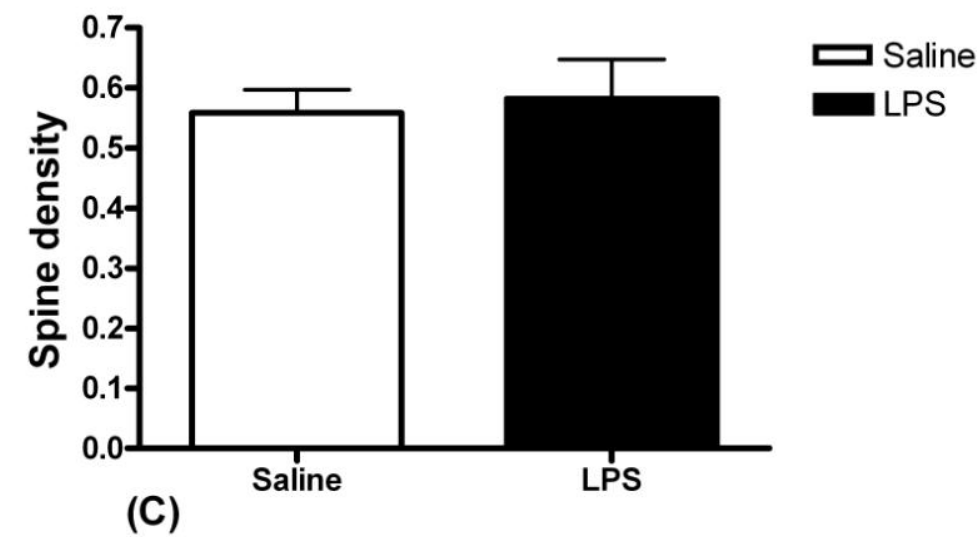


Fig. 5. Pyramidal neurons morphology in layer V PFC at P60. (A) Number of dendritic intersections per each Sholl radius $(10 \mu \mathrm{m})(P<0.001)$. (B) Total dendritic length $(\mu \mathrm{m})$ and $(\mathrm{C})$ Dendritic spine density (number of spines per10 $\mu \mathrm{m})(* P<0.05)$

\section{PFC layer V, P60}
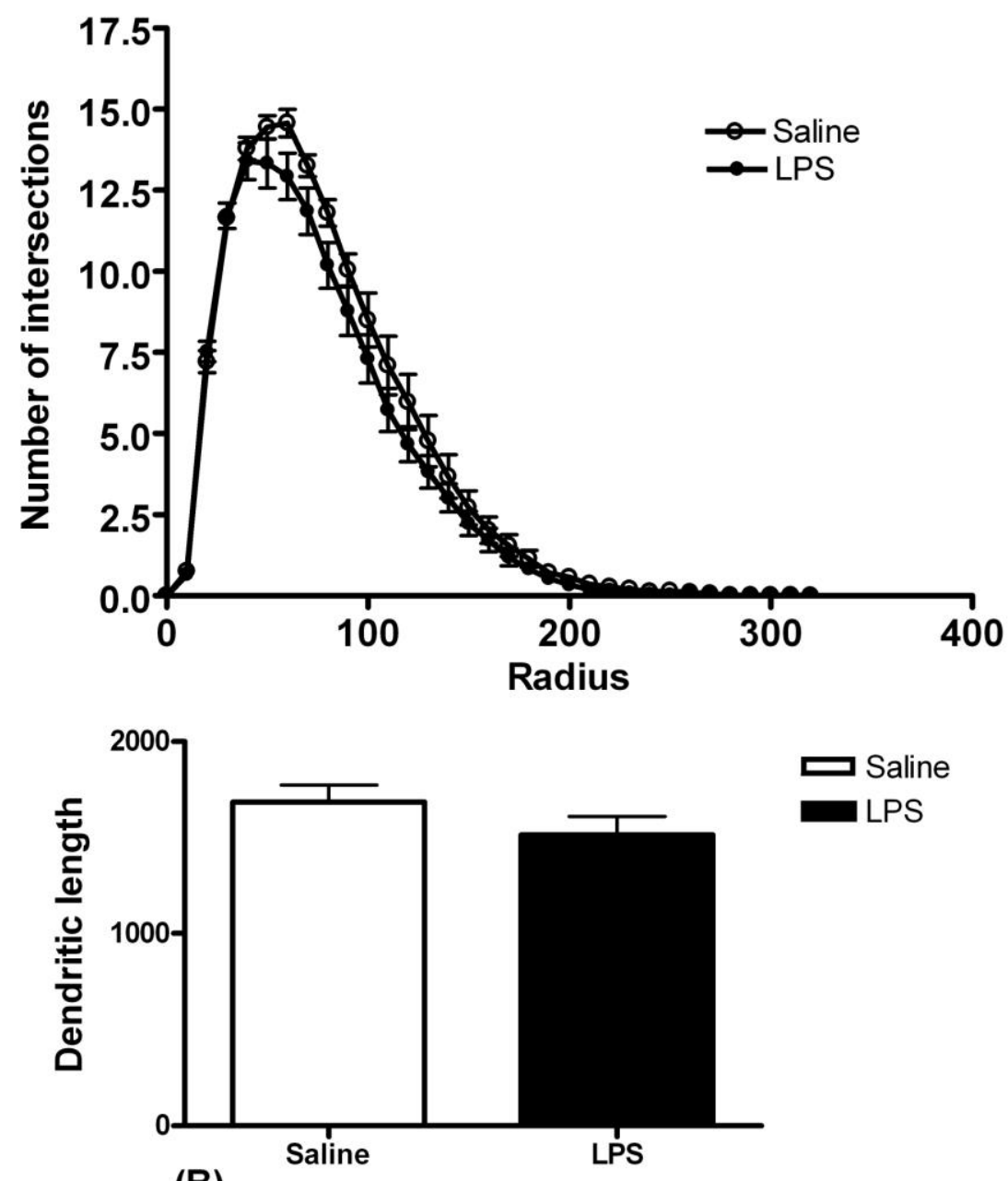

(B)

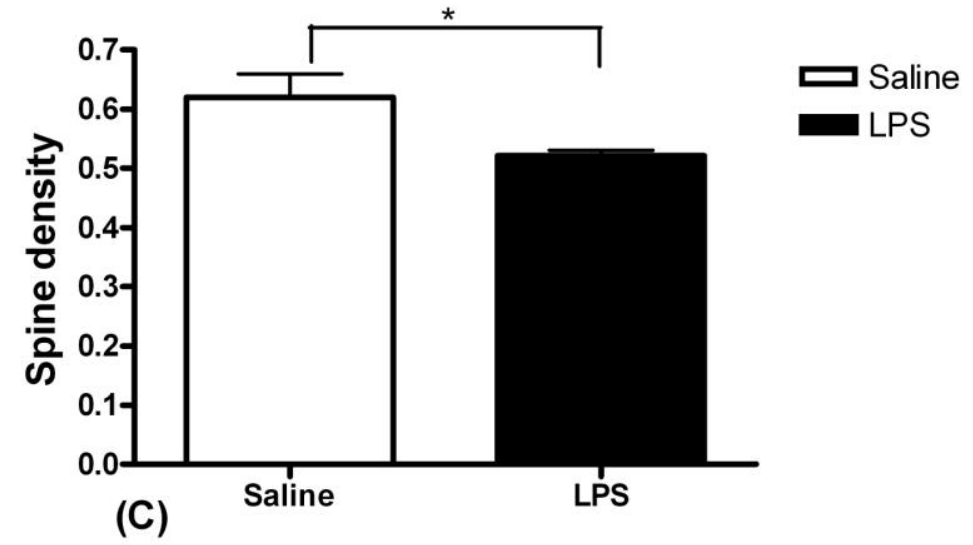


Fig. 6 . Pyramidal neuron morphology in CA1 at P10. (A) Number of dendritic intersections per each Sholl radius $(10 \mu \mathrm{m})(P<0.01)$. (B) Total dendritic length $(\mu \mathrm{m}),(\mathrm{C})$ Dendritic spine density (number of spines per $10 \mu \mathrm{m}),(\mathrm{D})$ spine length $(\mu \mathrm{m}),(\mathrm{E})$ spine surface $\left(\mu \mathrm{m}^{2}\right)$ and $(\mathrm{F})$ spine volume $\left(\mu \mathrm{m}^{3}\right)(* * P<0.01)$

\section{CA1, P10}

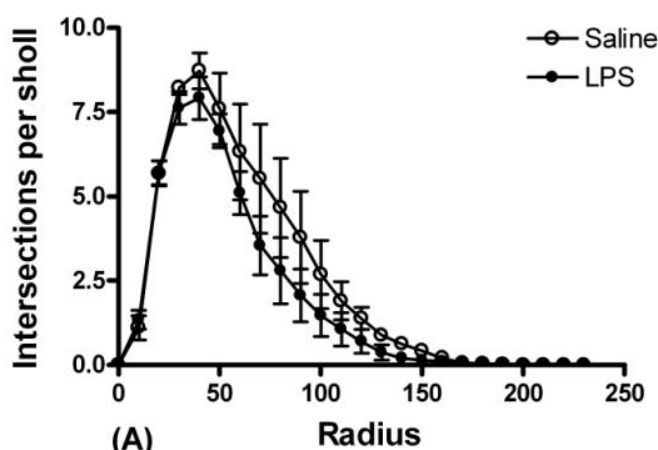

(A)
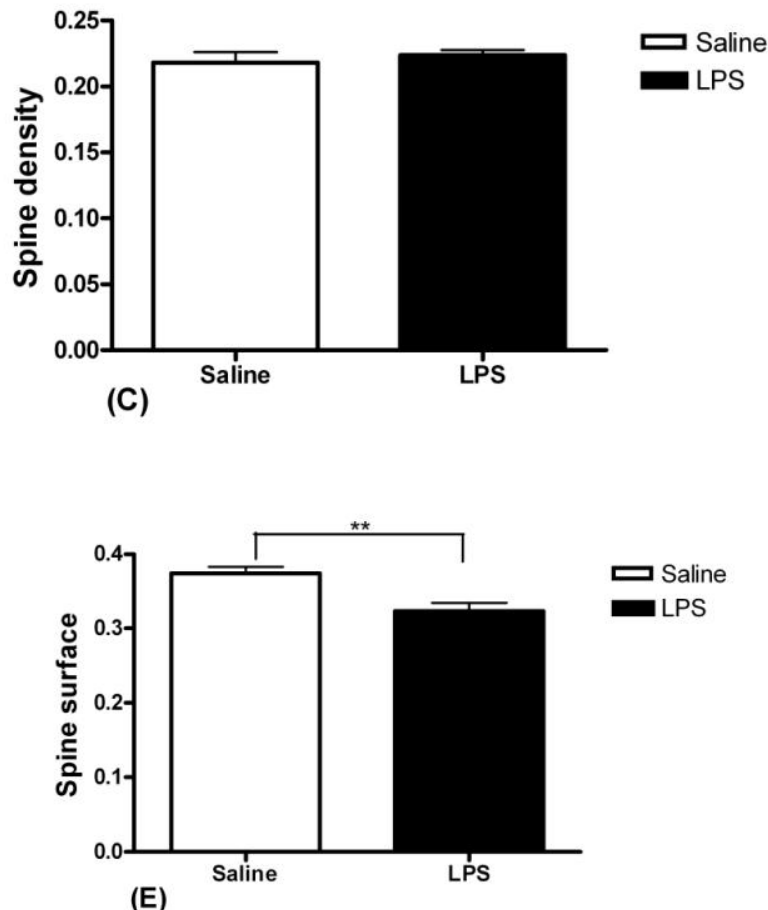

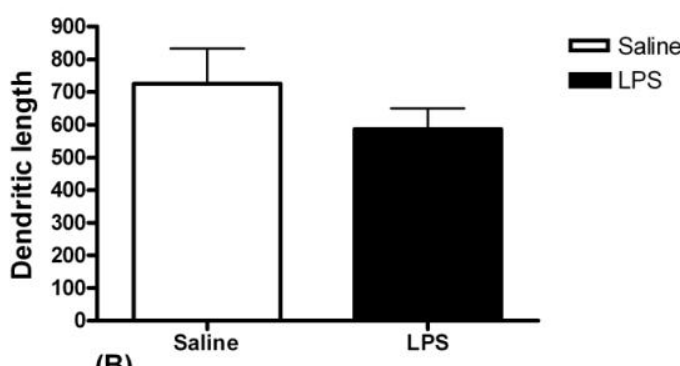

(B)

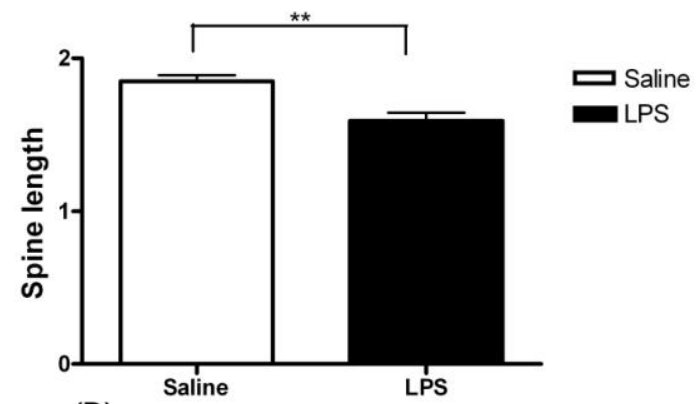

(D)

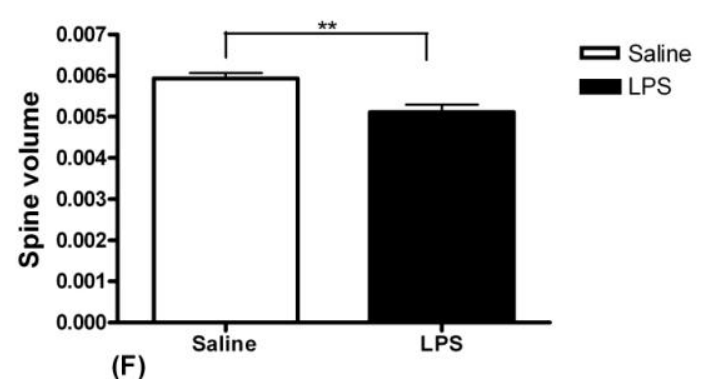


Fig. 7 . Pyramidal neuron morphology in hippocampus CA1 region at P35. (A) Number of dendritic intersections per each Sholl radius $(10 \mu \mathrm{m})(P<0.001)$. (B) Total dendritic length $(\mu \mathrm{m})$ and $(\mathrm{C})$ Dendritic spine density (number of spines per $10 \mu \mathrm{m}$ ).
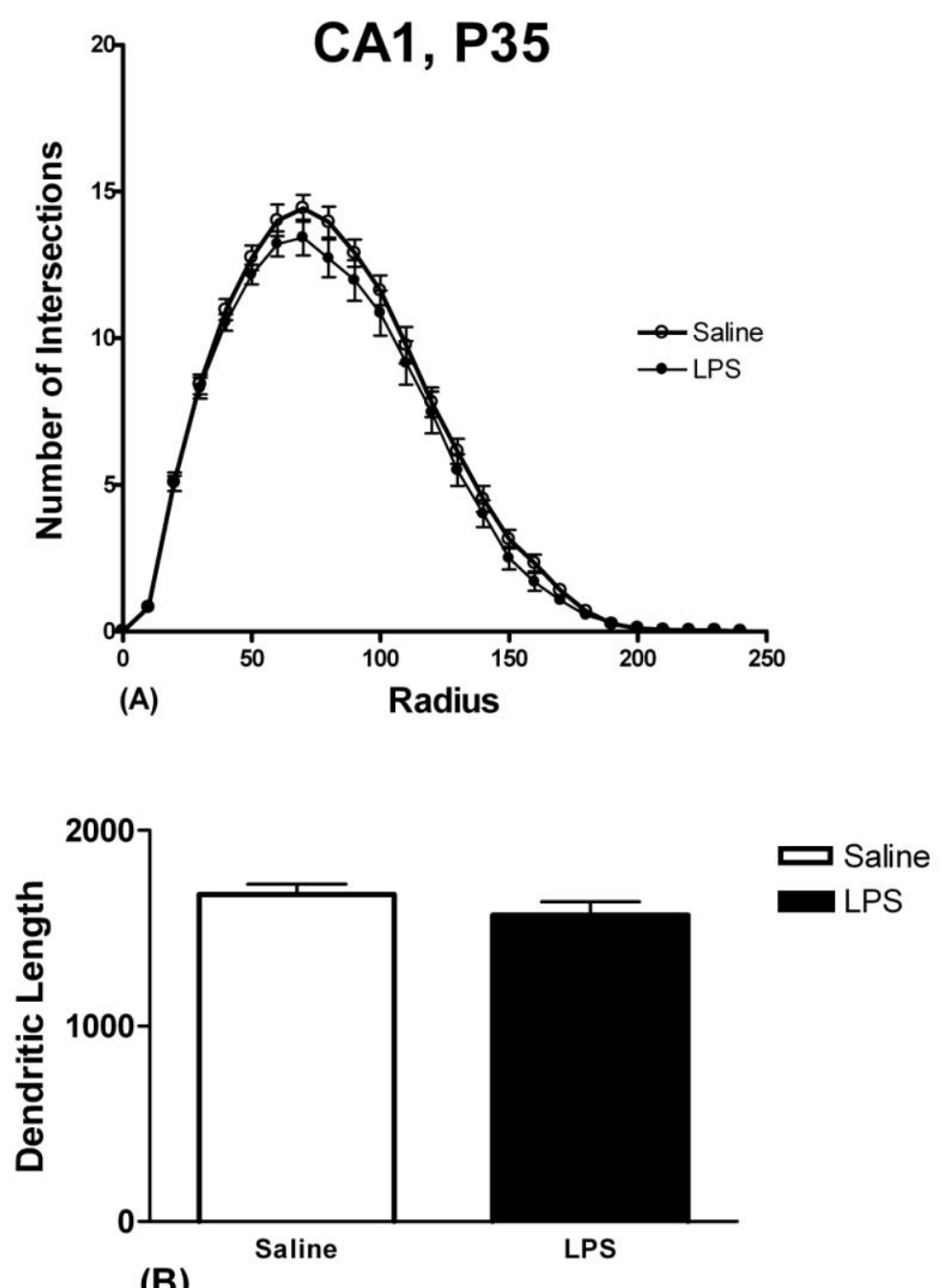

(B)

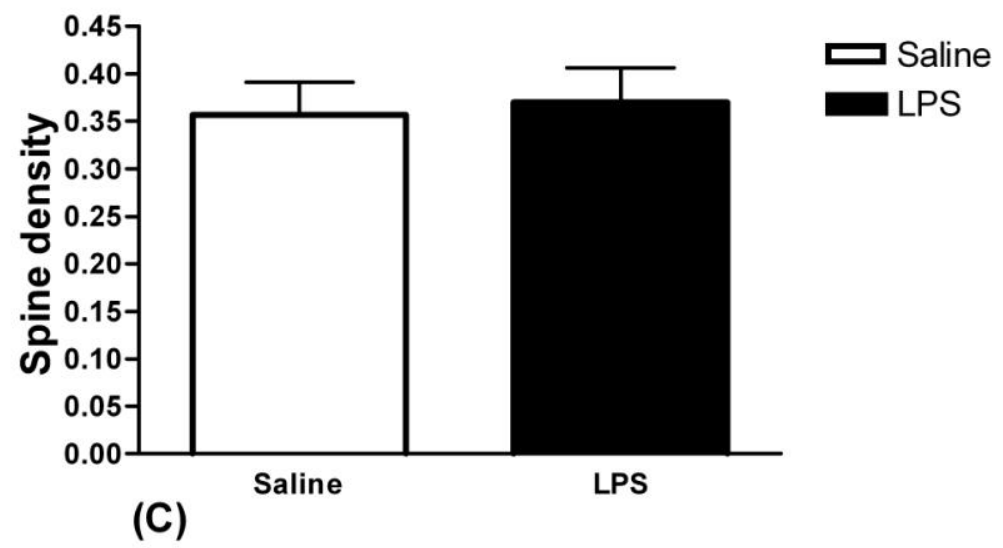


Fig. 8. Pyramidal neuron morphology in hippocampus CA1 region at P60. (A) Number of dendritic intersections per each Sholl radius $(10 \mu \mathrm{m})(P<0.001)($ Radius 80, 90 and 100 $* * P<0.01$, radius $110 * * * P<0.001$, radius 120 and $130 * P<0.05)$. (B) Total dendritic length $(\mu \mathrm{m})$ $(* P<0.05)$ and $(\mathrm{C})$ Dendritic spine density (number of spines per $10 \mu \mathrm{m}$ ).

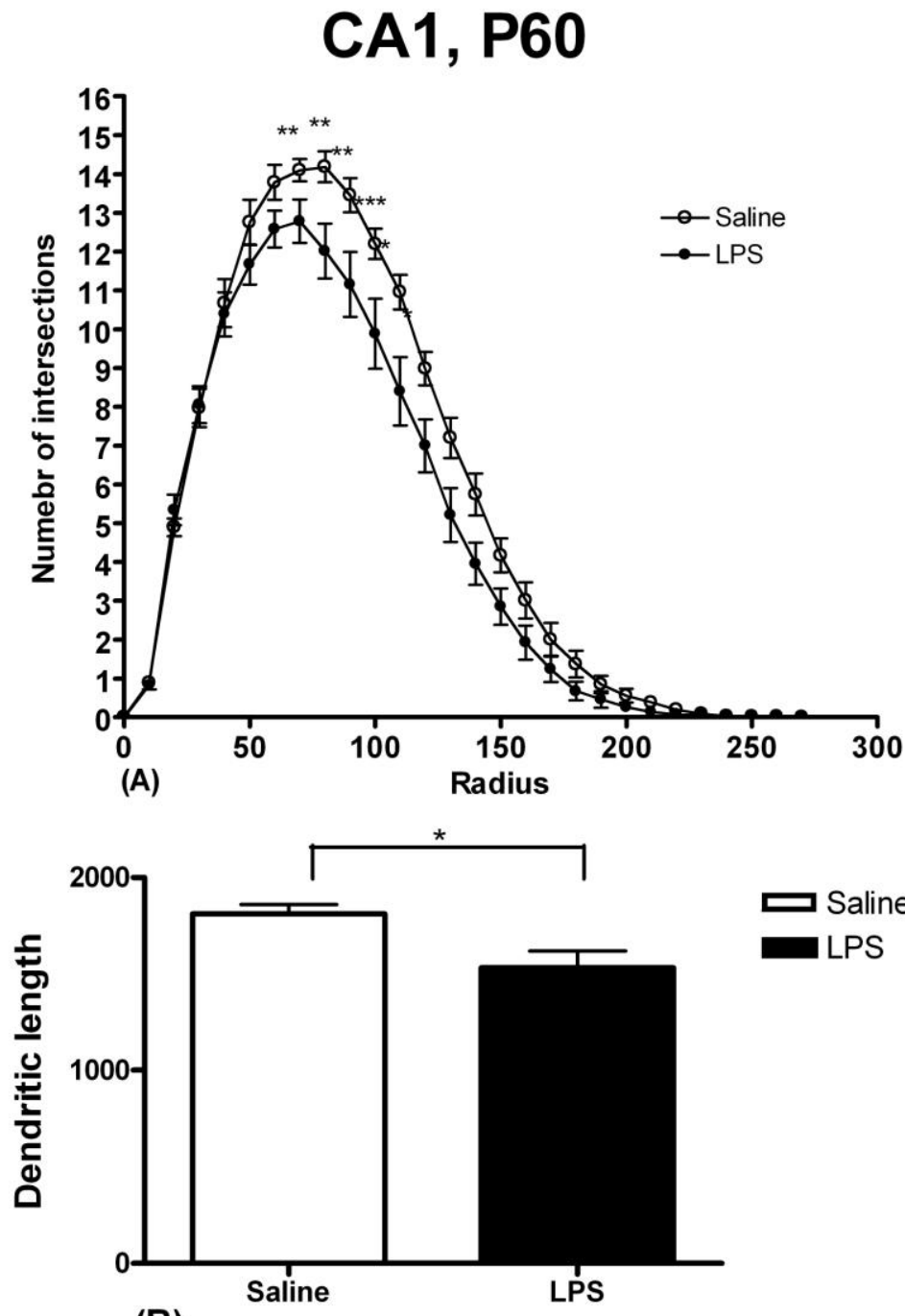

(B)

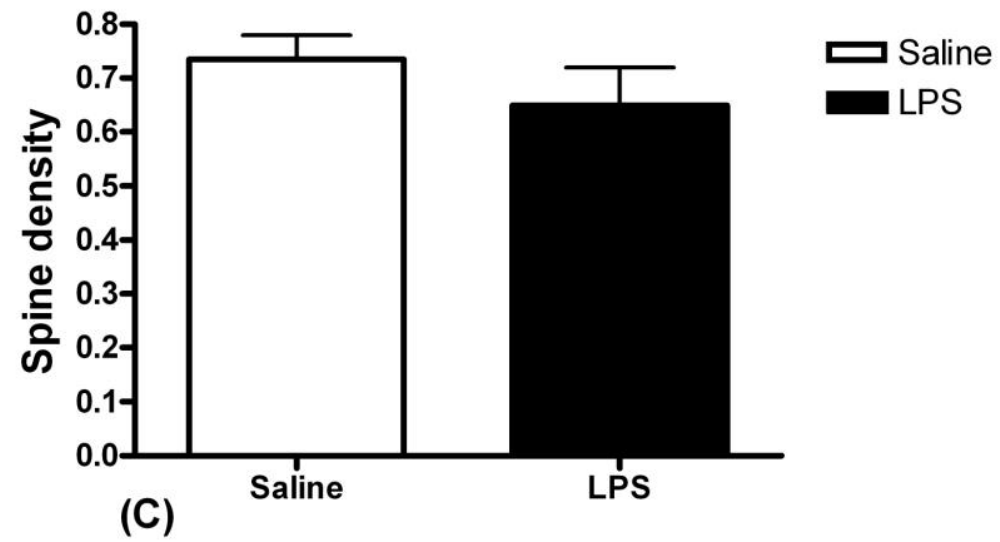


Fig. 9. Photomicrograph showing representative Golgi-Cox impregnated basilar dendrite from pyramidal neuron of layer V PFC at P60 in (A) Saline versus (B) LPS treated animals.

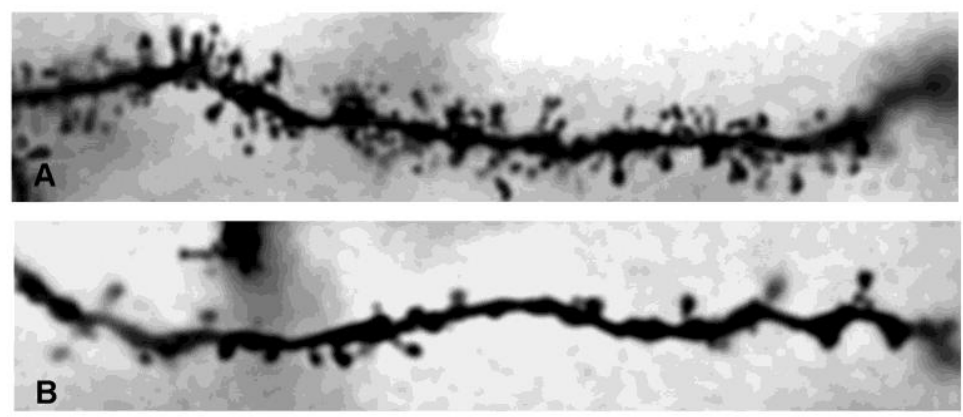




\section{Reference List}

1. Agnello D, Villa P, Ghezzi P (2000) Increased tumor necrosis factor and interleukin-6 production in the central nervous system of interleukin-10-deficient mice. Brain Res 869:241-243.

2. Ashdown H, Dumont Y, Ng M, Poole S, Boksa P, Luheshi GN (2006) The role of cytokines in mediating effects of prenatal infection on the fetus: implications for schizophrenia. Mol Psychiatry 11:47-55.

3. Ashdown H, Poole S, Boksa P, Luheshi GN (2007) Interleukin-1 receptor antagonist as a modulator of gender differences in the febrile response to lipopolysaccharide in rats. Am J Physiol Regul Integr Comp Physiol 292:R1667-R1674.

4. bdul-Monim Z, Neill JC, Reynolds GP (2007) Sub-chronic psychotomimetic phencyclidine induces deficits in reversal learning and alterations in parvalbuminimmunoreactive expression in the rat. J Psychopharmacol 21:198-205.

5. Beasley CL, Reynolds GP (1997) Parvalbumin-immunoreactive neurons are reduced in the prefrontal cortex of schizophrenics. Schizophr Res 24:349-355.

6. Beloosesky R, Gayle DA, Ross MG (2006) Maternal N-acetylcysteine suppresses fetal inflammatory cytokine responses to maternal lipopolysaccharide. American Journal of Obstetrics and Gynecology 195:1053-1057.

7. Black JE, Kodish IM, Grossman AW, Klintsova AY, Orlovskaya D, Vostrikov V, Uranova N, Greenough WT (2004) Pathology of layer V pyramidal neurons in the prefrontal cortex of patients with schizophrenia. Am J Psychiatry 161:742-744.

8. Blatteis CM, Sehic E (1998) Cytokines and fever. Ann N Y Acad Sci 840:608-618.

9. Boksa P, El-Khodor BF (2003) Birth insult interacts with stress at adulthood to alter dopaminergic function in animal models: possible implications for schizophrenia and other disorders. Neurosci Biobehav Rev 27:91-101.

10. Broadbelt K, Byne W, Jones LB (2002) Evidence for a decrease in basilar dendrites of pyramidal cells in schizophrenic medial prefrontal cortex. Schizophr Res 58:75-81.

11. Brown AS, Schaefer CA, Wyatt RJ, Goetz R, Begg MD, Gorman JM, Susser ES (2000) Maternal exposure to respiratory infections and adult schizophrenia spectrum disorders: a prospective birth cohort study. Schizophr Bull 26:287-295.

12. Brown AS, Susser ES (2002) In utero infection and adult schizophrenia. Ment Retard Dev Disabil Res Rev 8:51-57.

13. Cai ZW, Pan ZL, Pang Y, Evans OB, Rhodes PG (2000) Cytokine induction in fetal rat brains and brain injury in neonatal rats after maternal lipopolysaccharide administration. Pediatric Research 47:64-72. 
14. Cannon M, Clarke MC (2005) Risk for schizophrenia--broadening the concepts, pushing back the boundaries. Schizophr Res 79:5-13.

15. Carvey PM, Chang Q, Lipton JW, Ling Z (2003) Prenatal exposure to the bacteriotoxin lipopolysaccharide leads to long-term losses of dopamine neurons in offspring: a potential, new model of Parkinson's disease. Front Biosci 8:s826-s837.

16. Casanova MF, Rothberg B (2002b) Shape distortion of the hippocampus: a possible explanation of the pyramidal cell disarray reported in schizophrenia. Schizophr Res 55:19-24.

17. Casanova MF, Rothberg B (2002a) Shape distortion of the hippocampus: a possible explanation of the pyramidal cell disarray reported in schizophrenia. Schizophr Res 55:19-24.

18. Chattopadhyaya B, Di CG, Higashiyama H, Knott GW, Kuhlman SJ, Welker E, Huang ZJ (2004) Experience and activity-dependent maturation of perisomatic GABAergic innervation in primary visual cortex during a postnatal critical period. J Neurosci 24:9598-9611.

19. Clarke MC, Harley M, Cannon M (2006) The role of obstetric events in schizophrenia. Schizophr Bull 32:3-8.

20. Coe CL, Kramer M, Czeh B, Gould E, Reeves AJ, Kirschbaum C, Fuchs E (2003) Prenatal stress diminishes neurogenesis in the dentate gyrus of juvenile rhesus monkeys. Biol Psychiatry 54:1025-1034.

21. Colom LV, Castaneda MT, Reyna T, Hernandez S, Garrido-Sanabria E (2005) Characterization of medial septal glutamatergic neurons and their projection to the hippocampus. Synapse 58:151-164.

22. Dean K, Murray RM (2005) Environmental risk factors for psychosis. Dialogues Clin Neurosci 7:69-80.

23. Deumens R, Koopmans GC, Jaken RJ, Morren K, Comhair T, Kosar S, Steinbusch HW, Den Bakker CG, Joosten EA (2006) Stimulation of neurite outgrowth on neonatal cerebral astrocytes is enhanced in the presence of BDNF. Neurosci Lett 407:268-273.

24. Di CG (2007) Development of cortical GABAergic circuits and its implications for neurodevelopmental disorders. Clin Genet 72:1-8.

25. Ding DC, Gabbott PL, Totterdell S (2001) Differences in the laminar origin of projections from the medial prefrontal cortex to the nucleus accumbens shell and core regions in the rat. Brain Res 917:81-89.

26. Elovitz MA, Mrinalini C, Sammel MD (2006) Elucidating the early signal transduction pathways leading to fetal brain injury in preterm birth. Pediatr Res 59:50-55. 
27. Fan J, Wojnar MM, Theodorakis M, Lang CH (1996) Regulation of insulin-like growth factor (IGF)-I mRNA and peptide and IGF-binding proteins by interleukin-1. Am J Physiol 270:R621-R629.

28. Fatemi SH, Earle J, Kanodia R, Kist D, Emamian ES, Patterson PH, Shi L, Sidwell R (2002a) Prenatal viral infection leads to pyramidal cell atrophy and macrocephaly in adulthood: implications for genesis of autism and schizophrenia. Cell Mol Neurobiol 22:25-33.

29. Fatemi SH, Earle JA, McMenomy T (2000) Reduction in Reelin immunoreactivity in hippocampus of subjects with schizophrenia, bipolar disorder and major depression. Mol Psychiatry 5:654-63, 571.

30. Fatemi SH, Emamian ES, Kist D, Sidwell RW, Nakajima K, Akhter P, Shier A, Sheikh S, Bailey K (1999) Defective corticogenesis and reduction in Reelin immunoreactivity in cortex and hippocampus of prenatally infected neonatal mice. Mol Psychiatry 4:145-154.

31. Fatemi SH, Emamian ES, Sidwell RW, Kist DA, Stary JM, Earle JA, Thuras P (2002b) Human influenza viral infection in utero alters glial fibrillary acidic protein immunoreactivity in the developing brains of neonatal mice. Mol Psychiatry 7:633-640.

32. Fatemi SH, Reutiman TJ, Folsom TD, Huang H, Oishi K, Mori S, Smee DF, Pearce DA, Winter C, Sohr R, Juckel G (2008) Maternal infection leads to abnormal gene regulation and brain atrophy in mouse offspring: implications for genesis of neurodevelopmental disorders. Schizophr Res 99:56-70.

33. Fiala JC, Feinberg M, Popov V, Harris KM (1998) Synaptogenesis via dendritic filopodia in developing hippocampal area CA1. J Neurosci 18:8900-8911.

34. Flores C, Wen X, Labelle-Dumais C, Kolb B (2007) Chronic phencyclidine treatment increases dendritic spine density in prefrontal cortex and nucleus accumbens neurons. Synapse 61:978-984.

35. Flores G, Alquicer G, Silva-Gomez AB, Zaldivar G, Stewart J, Quirion R, Srivastava LK (2005) Alterations in dendritic morphology of prefrontal cortical and nucleus accumbens neurons in post-pubertal rats after neonatal excitotoxic lesions of the ventral hippocampus. Neuroscience 133:463-470.

36. Fortier ME, Joober R, Luheshi GN, Boksa P (2004) Maternal exposure to bacterial endotoxin during pregnancy enhances amphetamine-induced locomotion and startle responses in adult rat offspring. J Psychiatr Res 38:335-345.

37. Fortier ME, Luheshi GN, Boksa P (2007) Effects of prenatal infection on prepulse inhibition in the rat depend on the nature of the infectious agent and the stage of pregnancy. Behav Brain Res 181:270-277.

38. Fujioka A, Fujioka T, Ishida Y, Maekawa T, Nakamura S (2006) Differential effects of prenatal stress on the morphological maturation of hippocampal neurons. Neuroscience 141:907-915. 
39. Garey LJ, Ong WY, Patel TS, Kanani M, Davis A, Mortimer AM, Barnes TR, Hirsch SR (1998) Reduced dendritic spine density on cerebral cortical pyramidal neurons in schizophrenia. J Neurol Neurosurg Psychiatry 65:446-453.

40. Gayle DA, Beloosesky R, Desai M, Amidi F, Nunez SE, Ross MG (2004) Maternal LPS induces cytokines in the amniotic fluid and corticotropin releasing hormone in the fetal rat brain. American Journal of Physiology-Regulatory Integrative and Comparative Physiology 286:R1024-R1029.

41. Gibb R, Kolb B (1998) A method for vibratome sectioning of Golgi-Cox stained whole rat brain. J Neurosci Methods 79:1-4.

42. Gilmore J.H., Jarskog L.F., Swarooparani V, Lauder J.M. (2004) Prenatal Infection and Risk for Schizophrenia: IL-1?, IL-6, and TNF? Inhibit Cortical Neuron Dendrite Development. Neuropsychopharmacology 29:1221-1229.

43. Gilmore JH, Jarskog LF, Vadlamudi S (2003) Maternal infection regulates BDNF and NGF expression in fetal and neonatal brain and maternal-fetal unit of the rat. $\mathbf{J}$ Neuroimmunol 138:49-55.

44. Gilmore JH, Jarskog LF, Vadlamudi S (2005) Maternal poly I : C exposure during pregnancy regulates TNF alpha BDNF, and NGF expression in neonatal brain and the maternal-fetal unit of the rat. Journal of Neuroimmunology 159:106-112.

45. Glantz LA, Lewis DA (2000) Decreased dendritic spine density on prefrontal cortical pyramidal neurons in schizophrenia. Arch Gen Psychiatry 57:65-73.

46. Guan Z, Fang J (2006) Peripheral immune activation by lipopolysaccharide decreases neurotrophins in the cortex and hippocampus in rats. Brain Behav Immun 20:64-71.

47. Hajszan T, Leranth C, Roth RH (2006) Subchronic phencyclidine treatment decreases the number of dendritic spine synapses in the rat prefrontal cortex. Biol Psychiatry 60:639644.

48. Harris KM (1999) Structure, development, and plasticity of dendritic spines. Curr Opin Neurobiol 9:343-348.

49. Harrison PJ, Weinberger DR (2005) Schizophrenia genes, gene expression, and neuropathology: on the matter of their convergence. Mol Psychiatry 10:40-68.

50. Heinz A, Romero B, Gallinat J, Juckel G, Weinberger DR (2003) Molecular brain imaging and the neurobiology and genetics of schizophrenia. Pharmacopsychiatry 36 Suppl 3:S152-S157.

51. Hikida T, Jaaro-Peled H, Seshadri S, Oishi K, Hookway C, Kong S, Wu D, Xue R, Andrade M, Tankou S, Mori S, Gallagher M, Ishizuka K, Pletnikov M, Kida S, Sawa A (2007) Dominant-negative DISC1 transgenic mice display schizophrenia-associated phenotypes detected by measures translatable to humans. Proc Natl Acad Sci U S A 104:14501-14506. 
52. Jan YN, Jan LY (2003) The control of dendrite development. Neuron 40:229-242.

53. Jeohn GH, Kong LY, Wilson B, Hudson P, Hong JS (1998) Synergistic neurotoxic effects of combined treatments with cytokines in murine primary mixed neuron/glia cultures. J Neuroimmunol 85:1-10.

54. Juarez I, Gratton A, Flores G (2008) Ontogeny of altered dendritic morphology in the rat prefrontal cortex, hippocampus, and nucleus accumbens following Cesarean delivery and birth anoxia. J Comp Neurol 507:1734-1747.

55. Kajiwara R, Wouterlood FG, Sah A, Boekel AJ, Baks-te Bulte LT, Witter MP (2008) Convergence of entorhinal and CA3 inputs onto pyramidal neurons and interneurons in hippocampal area CA1--an anatomical study in the rat. Hippocampus 18:266-280.

56. Kalus P, Muller TJ, Zuschratter W, Senitz D (2000) The dendritic architecture of prefrontal pyramidal neurons in schizophrenic patients. Neuroreport 11:3621-3625.

57. Kawamura T, Chen J, Takahashi T, Ichitani Y, Nakahara D (2006) Prenatal stress suppresses cell proliferation in the early developing brain. Neuroreport 17:1515-1518.

58. Kessler JA, Mehler MF, Michaelson MD (1998) Effects of cytokines on neuronal development. Journal of Neurochemistry 70:S60.

59. Khashan AS, Abel KM, McNamee R, Pedersen MG, Webb RT, Baker PN, Kenny LC, Mortensen PB (2008) Higher risk of offspring schizophrenia following antenatal maternal exposure to severe adverse life events. Arch Gen Psychiatry 65:146-152.

60. Kim IJ, Beck HN, Lein PJ, Higgins D (2002) Interferon gamma induces retrograde dendritic retraction and inhibits synapse formation. J Neurosci 22:4530-4539.

61. Kolluri N, Sun Z, Sampson AR, Lewis DA (2005) Lamina-specific reductions in dendritic spine density in the prefrontal cortex of subjects with schizophrenia. Am J Psychiatry 162:1200-1202.

62. Kremlev SG, Palmer C (2005) Interleukin-10 inhibits endotoxin-induced proinflammatory cytokines in microglial cell cultures. J Neuroimmunol 162:71-80.

63. Kuroda M, Yokofujita J, Murakami K (1998) An ultrastructural study of the neural circuit between the prefrontal cortex and the mediodorsal nucleus of the thalamus. Prog Neurobiol 54:417-458.

64. Labelle C, Leclerc N (2000) Exogenous BDNF, NT-3 and NT-4 differentially regulate neurite outgrowth in cultured hippocampal neurons. Brain Res Dev Brain Res 123:1-11.

65. Lante F, Meunier J, Guiramand J, Maurice T, Cavalier M, de Jesus Ferreira MC, Aimar R, Cohen-Solal C, Vignes M, Barbanel G (2007) Neurodevelopmental damage after prenatal infection: role of oxidative stress in the fetal brain. Free Radic Biol Med 42:1231-1245. 
66. Lemaire V, Koehl M, Le MM, Abrous DN (2000) Prenatal stress produces learning deficits associated with an inhibition of neurogenesis in the hippocampus. Proc Natl Acad Sci U S A 97:11032-11037.

67. Ling Z, Gayle DA, Ma SY, Lipton JW, Tong CW, Hong JS, Carvey PM (2002) In utero bacterial endotoxin exposure causes loss of tyrosine hydroxylase neurons in the postnatal rat midbrain. Mov Disord 17:116-124.

68. Lynch AM, Walsh C, Delaney A, Nolan Y, Campbell VA, Lynch MA (2004) Lipopolysaccharide-induced increase in signalling in hippocampus is abrogated by IL-10-a role for IL-1 beta? J Neurochem 88:635-646.

69. MacLaurin SA, Krucker T, Fish KN (2007) Hippocampal dendritic arbor growth in vitro: regulation by Reelin-Disabled-1 signaling. Brain Res 1172:1-9.

70. MalekAhmadi P (1996) Neuropsychiatric aspects of cytokines research: An overview. Neuroscience and Biobehavioral Reviews 20:359-365.

71. Mandyam CD, Crawford EF, Eisch AJ, Rivier CL, Richardson HN (2008) Stress experienced in utero reduces sexual dichotomies in neurogenesis, microenvironment, and cell death in the adult rat hippocampus. Dev Neurobiol 68:575-589.

72. Marenco S, Weinberger DR (2000) The neurodevelopmental hypothesis of schizophrenia: following a trail of evidence from cradle to grave. Dev Psychopathol 12:501-527.

73. Marx CE, Jarskog LF, Lauder JM, Lieberman JA, Gilmore JH (2001) Cytokine effects on cortical neuron MAP-2 immunoreactivity: Implications for schizophrenia. Biological Psychiatry 50:743-749.

74. McClellan JM, Susser E, King MC (2006) Maternal famine, de novo mutations, and schizophrenia. JAMA 296:582-584.

75. McDonald C, Murray RM (2000) Early and late environmental risk factors for schizophrenia. Brain Res Brain Res Rev 31:130-137.

76. Merrill JE (1992) Tumor-Necrosis-Factor-Alpha, Interleukin-1 and Related Cytokines in Brain-Development - Normal and Pathological. Developmental Neuroscience 14:1-10.

77. Meyer U, Feldon J, Schedlowski M, Yee BK (2006a) Immunological stress at the maternal-foetal interface: A link between neurodevelopment and adult psychopathology. Brain Behavior and Immunity 20:378-388.

78. Meyer U, Feldon J, Schedlowski M, Yee BK (2006b) Immunological stress at the maternal-foetal interface: a link between neurodevelopment and adult psychopathology. Brain Behav Immun 20:378-388. 
79. Meyer U, Nyffeler M, Engler A, Urwyler A, Schedlowski M, Knuesel I, Yee BK, Feldon $\mathrm{J}$ (2006c) The time of prenatal immune challenge determines the specificity of inflammation-mediated brain and behavioral pathology. J Neurosci 26:4752-4762.

80. Meyer U, Nyffeler M, Schwendener S, Knuesel I, Yee BK, Feldon J (2007a) Relative Prenatal and Postnatal Maternal Contributions to Schizophrenia-Related Neurochemical Dysfunction after In Utero Immune Challenge. Neuropsychopharmacology.

81. Meyer U, Nyffeler M, Yee BK, Knuesel I, Feldon J (2007b) Adult brain and behavioral pathological markers of prenatal immune challenge during early/middle and late fetal development in mice. Brain Behav Immun.

82. Meyer U, Nyffeler M, Yee BK, Knuesel I, Feldon J (2007c) Adult brain and behavioral pathological markers of prenatal immune challenge during early/middle and late fetal development in mice. Brain Behav Immun.

83. Michelsen KA, Van den Hove DL, Schmitz C, Segers O, Prickaerts J, Steinbusch HW (2007) Prenatal stress and subsequent exposure to chronic mild stress influence dendritic spine density and morphology in the rat medial prefrontal cortex. BMC Neurosci 8:107.

84. Murmu MS, Salomon S, Biala Y, Weinstock M, Braun K, Bock J (2006) Changes of spine density and dendritic complexity in the prefrontal cortex in offspring of mothers exposed to stress during pregnancy. Eur J Neurosci 24:1477-1487.

85. Neumann H, Schweigreiter R, Yamashita T, Rosenkranz K, Wekerle H, Barde YA (2002) Tumor necrosis factor inhibits neurite outgrowth and branching of hippocampal neurons by a rho-dependent mechanism. J Neurosci 22:854-862.

86. Ning H, Wang H, Zhao L, Zhang C, Li XY, Chen YH, Xu DX (2008) Maternallyadministered lipopolysaccharide (LPS) increases tumor necrosis factor alpha in fetal liver and fetal brain: its suppression by low-dose LPS pretreatment. Toxicol Lett 176:13-19.

87. Nyffeler M, Meyer U, Yee BK, Feldon J, Knuesel I (2006) Maternal immune activation during pregnancy increases limbic GABAA receptor immunoreactivity in the adult offspring: implications for schizophrenia. Neuroscience 143:51-62.

88. Olson EC, Kim S, Walsh CA (2006) Impaired neuronal positioning and dendritogenesis in the neocortex after cell-autonomous Dab1 suppression. J Neurosci 26:1767-1775.

89. Onn SP, Wang XB, Lin M, Grace AA (2006) Dopamine D1 and D4 receptor subtypes differentially modulate recurrent excitatory synapses in prefrontal cortical pyramidal neurons. Neuropsychopharmacology 31:318-338.

90. Ozawa K, Hashimoto K, Kishimoto T, Shimizu E, Ishikura H, Iyo M (2006) Immune activation during pregnancy in mice leads to dopaminergic hyperfunction and cognitive impairment in the offspring: a neurodevelopmental animal model of schizophrenia. Biol Psychiatry 59:546-554. 
91. Paintlia MK, Paintlia AS, Barbosa E, Singh I, Singh AK (2004) N-acetylcysteine prevents endotoxin-induced degeneration of oligodendrocyte progenitors and hypomyelination in developing rat brain. Journal of Neuroscience Research 78:347-361.

92. Patterson PH (2002) Maternal infection: window on neuroimmune interactions in fetal brain development and mental illness. Curr Opin Neurobiol 12:115-118.

93. Patterson PH, Nawa H (1993) Neuronal Differentiation Factors Cytokines and Synaptic Plasticity. Cell 72:123-137.

94. Paxinos G, Watson C (1986) The rat brain in streaptaxic coordinates. New york: Academic Press.

95. Paxinos G, Watson C (2007) The rat brain in stereotaxic coordinates. New York: Academic Press.

96. Penner JD, Brown AS (2007) Prenatal infectious and nutritional factors and risk of adult schizophrenia. Expert Rev Neurother 7:797-805.

97. Reynolds GP, Beasley CL, Zhang ZJ (2002) Understanding the neurotransmitter pathology of schizophrenia: selective deficits of subtypes of cortical GABAergic neurons. J Neural Transm 109:881-889.

98. Ring RH, Alder J, Fennell M, Kouranova E, Black IB, Thakker-Varia S (2006) Transcriptional profiling of brain-derived-neurotrophic factor-induced neuronal plasticity: a novel role for nociceptin in hippocampal neurite outgrowth. J Neurobiol 66:361-377.

99. Rivera DL, Olister SM, Liu X, Thompson JH, Zhang XJ, Pennline K, Azuero R, Clark DA, Miller MJ (1998) Interleukin-10 attenuates experimental fetal growth restriction and demise. FASEB J 12:189-197.

100. Romero E, Guaza C, Castellano B, Borrell J (2008) Ontogeny of sensorimotor gating and immune impairment induced by prenatal immune challenge in rats: implications for the etiopathology of schizophrenia. Mol Psychiatry.

101. Rothwell NJ, Hopkins SJ (1995) Cytokines and the Nervous-System .2. Actions and Mechanisms of Action. Trends in Neurosciences 18:130-136.

102. Rousset CI, Chalon S, Cantagrel S, Bodard S, Andres C, Gressens P, Saliba E (2006) Maternal exposure to LPS induces hypomyelination in the internal capsule and programmed cell death in the deep gray matter in newborn rats. Pediatr Res 59:428-433.

103. Samuelsson AM, Jennische E, Hansson HA, Holmang A (2006) Prenatal exposure to interleukin-6 results in inflammatory neurodegeneration in hippocampus with NMDA/GABA(A) dysregulation and impaired spatial learning. Am J Physiol Regul Integr Comp Physiol 290:R1345-R1356. 
104. Schnydrig S, Korner L, Landweer S, Ernst B, Walker G, Otten U, Kunz D (2007) Peripheral lipopolysaccharide administration transiently affects expression of brainderived neurotrophic factor, corticotropin and proopiomelanocortin in mouse brain. Neurosci Lett 429:69-73.

105. Scott EK, Luo L (2001) How do dendrites take their shape? Nat Neurosci 4:359-365.

106. Seamans JK, Yang CR (2004) The principal features and mechanisms of dopamine modulation in the prefrontal cortex. Prog Neurobiol 74:1-58.

107. Sharangpani A, Takanohashi A, Bell MJ (2008) Caspase activation in fetal rat brain following experimental intrauterine inflammation. Brain Res 1200C:138-145.

108. Shi L, Fatemi SH, Sidwell RW, Patterson PH (2003) Maternal influenza infection causes marked behavioral and pharmacological changes in the offspring. J Neurosci 23:297-302.

109. Smith SE, Li J, Garbett K, Mirnics K, Patterson PH (2008) Interleukin-6 mediates the effects of maternal immune activation on the behavior and gene expression of the offspring. Journal of Neurochemistry 104:150.

110. Smith SE, Li J, Garbett K, Mirnics K, Patterson PH (2007) Maternal immune activation alters fetal brain development through interleukin-6. J Neurosci 27:10695-10702.

111. Spencer KM, Nestor PG, Niznikiewicz MA, Salisbury DF, Shenton ME, McCarley RW (2003) Abnormal neural synchrony in schizophrenia. J Neurosci 23:7407-7411.

112. Spencer KM, Nestor PG, Perlmutter R, Niznikiewicz MA, Klump MC, Frumin M, Shenton ME, McCarley RW (2004) Neural synchrony indexes disordered perception and cognition in schizophrenia. Proc Natl Acad Sci U S A 101:17288-17293.

113. Tohmi M, Tsuda N, Watanabe Y, Kakita A, Nawa H (2004) Perinatal inflammatory cytokine challenge results in distinct neurobehavioral alterations in rats: implication in psychiatric disorders of developmental origin. Neurosci Res 50:67-75.

114. Urakubo A, Jarskog LF, Lieberman JA, Gilmore JH (2001) Prenatal exposure to maternal infection alters cytokine expression in the placenta, amniotic fluid, and fetal brain. Schizophr Res 47:27-36.

115. Wang CC, Shyu BC (2004) Differential projections from the mediodorsal and centrolateral thalamic nuclei to the frontal cortex in rats. Brain Res 995:226-235.

116. Wang HD, Deutch AY (2007) Dopamine Depletion of the Prefrontal Cortex Induces Dendritic Spine Loss: Reversal by Atypical Antipsychotic Drug Treatment. Neuropsychopharmacology.

117. Wang X, Hagberg H, Zhu C, Jacobsson B, Mallard C (2007) Effects of intrauterine inflammation on the developing mouse brain. Brain Res 1144:180-185. 
118. Wang X, Rousset CI, Hagberg H, Mallard C (2006) Lipopolysaccharide-induced inflammation and perinatal brain injury. Semin Fetal Neonatal Med 11:343-353.

119. Watanabe Y, Hashimoto S, Kakita A, Takahashi H, Ko J, Mizuno M, Someya T, Patterson PH, Nawa H (2004) Neonatal impact of leukemia inhibitory factor on neurobehavioral development in rats. Neurosci Res 48:345-353.

120. Wedzony K, Fijal K, Mackowiak M (2005) Alterations in the dendritic morphology of prefrontal pyramidal neurons in adult rats after blockade of NMDA receptors in the postnatal period. Brain Res 1062:166-170.

121. Woo NH, Lu B (2006) Regulation of cortical interneurons by neurotrophins: from development to cognitive disorders. Neuroscientist 12:43-56.

122. Yolken RH, Torrey EF (2008) Are some cases of psychosis caused by microbial agents? A review of the evidence. Mol Psychiatry.

123. Zuckerman L, Rehavi M, Nachman R, Weiner I (2003) Immune activation during pregnancy in rats leads to a postpubertal emergence of disrupted latent inhibition, dopaminergic hyperfunction, and altered limbic morphology in the offspring: a novel neurodevelopmental model of schizophrenia. Neuropsychopharmacology 28:1778-1789.

124. Zuckerman L, Weiner I (2005) Maternal immune activation leads to behavioral and pharmacological changes in the adult offspring. J Psychiatr Res 39:311-323. 